\title{
HEALTH PERCEPTIONS AND EXPERIENCES OF CANTONESE-SPEAKING OLDER IMMIGRANT WOMEN FROM MAINLAND CHINA LIVING IN TORONTO
}

by

Alicia W. Fong, B.A. Honours, Concordia University, 2014

\author{
A Major Research Paper \\ presented to Ryerson University \\ in partial fulfillment of the requirements for the degree of \\ Master of Arts \\ In the Program of \\ Immigration and Settlement Studies
}

Toronto, Ontario, Canada, 2015

(C) Alicia W. Fong 2015 


\begin{abstract}
AUTHOR'S DECLARATION
I hereby declare that I am the sole author of this Major Research Paper. This is a true copy of the MRP, including any required final revisions, as accepted by my examiners.

I authorize Ryerson University to lend this MRP to other institutions or individuals for the purpose of scholarly research.

I further authorize Ryerson University to reproduce this MRP by photocopying or by other means, in total or in part, at the request of other institutions or individuals for the purpose of scholarly research.
\end{abstract}

I understand that my MRP may be made electronically available to the public.

Alicia W. Fong 
Health Perceptions and Experiences of Cantonese-speaking Older Immigrant Women from Mainland China Living in Toronto

\author{
Alicia W. Fong \\ Master of Arts 2015 \\ Immigration and Settlement Studies \\ Ryerson University
}

\begin{abstract}
Few health studies have been conducted in a non-official language with participants. In addition, few studies have attempted to discover the social determinants of health to account for health inequalities for immigrant women through qualitative interviews (Hyman, 2007). This study endeavoured to understand the perceptions of health and the experiences of healthcare services in Toronto by Cantonese-speaking older immigrant women. The study was conducted in their own language. In addition to the Cantonese-speaking older immigrant women, community workers who work with Chinese immigrant clients were also interviewed. The social determinants of health were divided into post-migration challenges and systemic barriers, then analyzed with an intersectional theoretical framework. This study highlights the importance of an intersectional approach since many social determinants influenced the participants' health experiences. Furthermore, this study underlines the need to advocate for immigrant health to take prominence in national health policy in Canada.
\end{abstract}

Key words: Chinese, immigrant women, health, older adults, language 


\section{ACKNOWLEDGEMENTS}

I would like to thank my participants and various workers in community organizations for their time and efforts in assisting with my project. Without their interest and support, my project would not be possible. I would also like to thank my mother for her help with some Cantonese translations.

Thank you to my supervisor, Dr. Sepali Guruge for her support, contributions, and guidance throughout the project. Also thank you to Dr. Lu Wang as my second reader for her input with my MRP.

I would also like to thank A.C. for assistance in translating some of my project documents from English into Traditional Chinese. 


\section{DEDICATION}

For the women in my family: my mother, my poh poh who cannot speak English, and my ma ma who I never met but deserved a better fate.

Also, in memory of my grandfather who passed away during the summer when this MRP was in progress.

Finally, in memory of my great-grandfather who immigrated to Canada approximately a century ago, and who persevered despite racist measures such as the Chinese Exclusion Act. 


\section{Table of Contents}

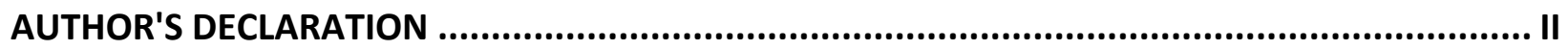

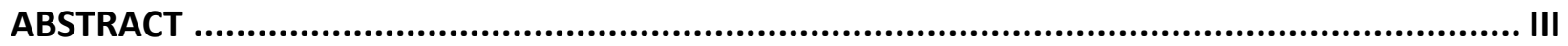

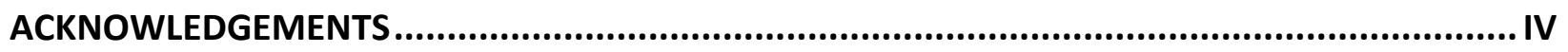

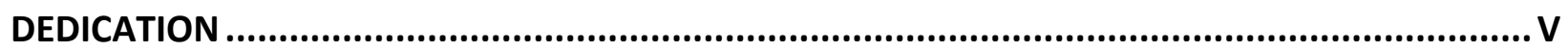

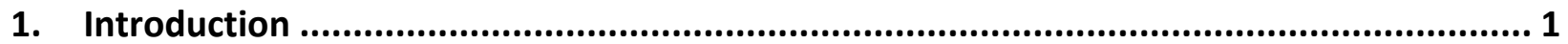

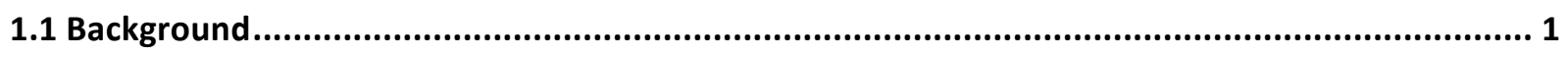

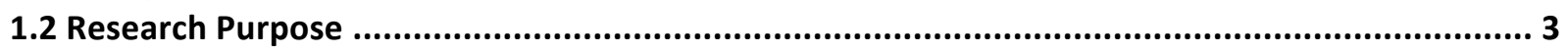

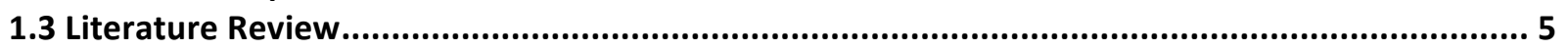

1.3.1 Historical Context of Chinese Women in Canada............................................................

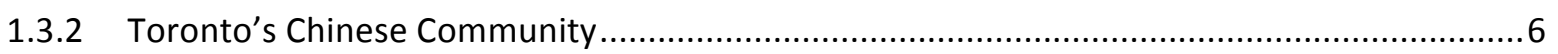

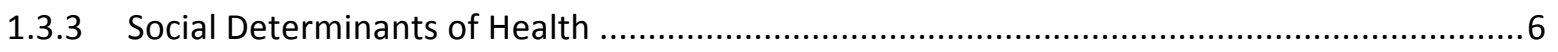

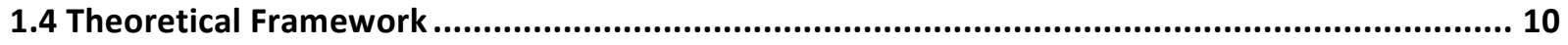

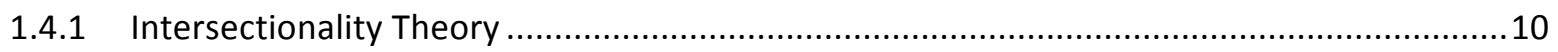

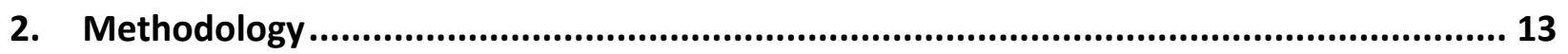

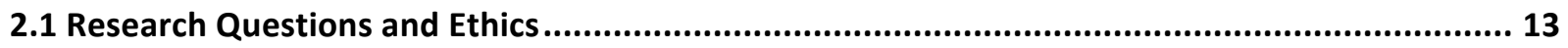

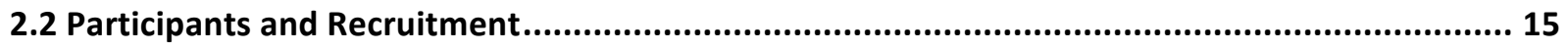

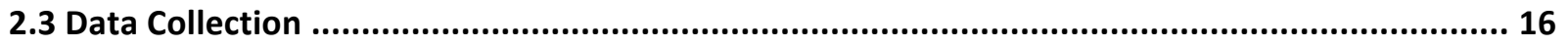

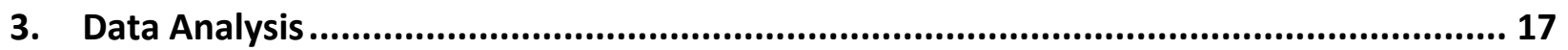

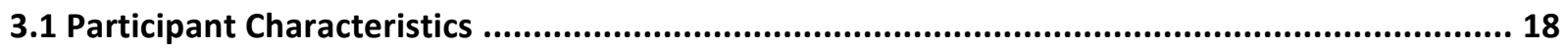

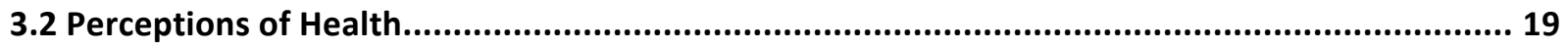

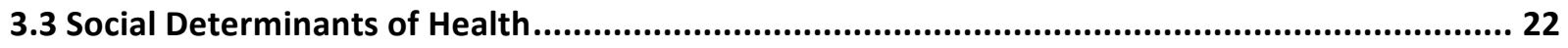

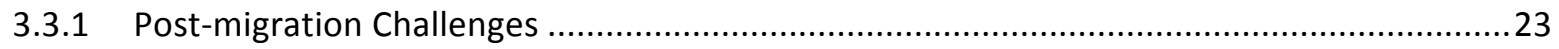

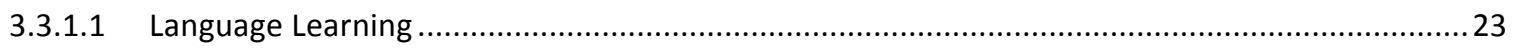

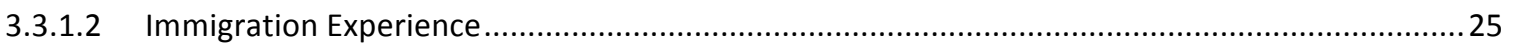

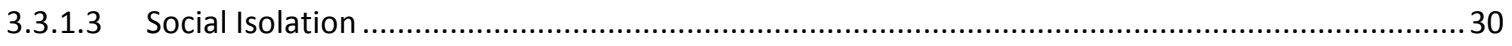

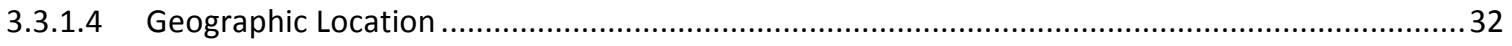

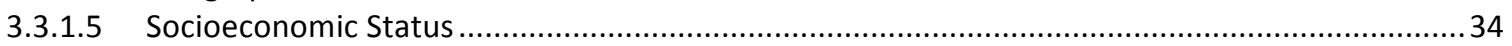

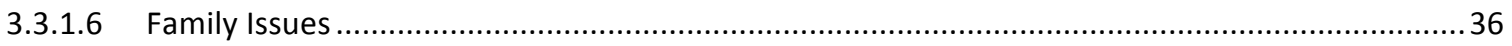

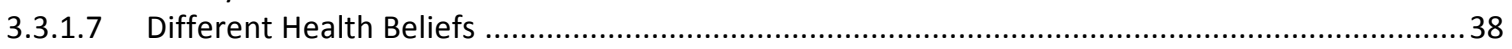

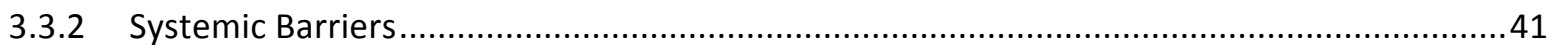

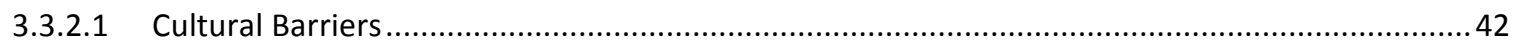

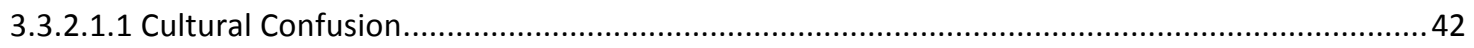

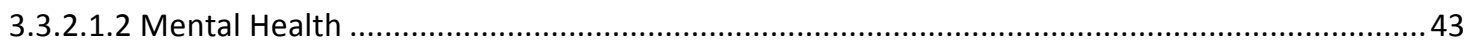

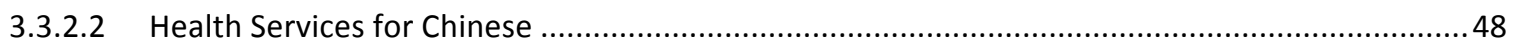

3.3.2.3 Participant Recommendations and Government Funding .................................................... 50

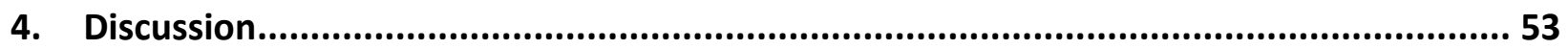

4.1 Intersecting Family Issues with other Post-migration Challenges......................................... 53

4.2 Intersecting Chinese Culture and Health Beliefs with Canadian Culture and Health Beliefs....... 56

4.3 Intersecting Immigration Experiences with Social Categories ............................................ 58

4.4 Intersecting Government Funding for the Healthcare System with Culture ............................. 61

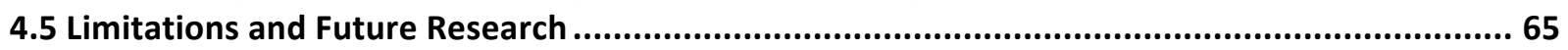




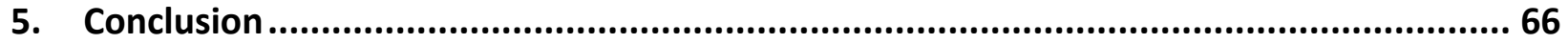

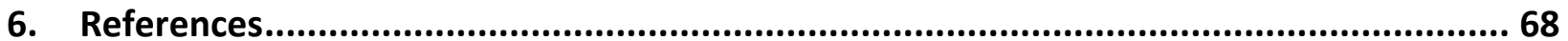




\section{Introduction}

\subsection{Background}

Healthcare is an essential service for every human being. Canada signed the United Nations' Universal Declaration of Human Rights, Article 25 (1948), which declared that everyone has the right to good health and well-being for themselves and their family, including access to medical care. Institutional factors (i.e., health care system, medical professionals) or post-migration challenges (i.e., immigration status, language) are barriers to Canadian healthcare that exist for immigrants (Asanin \& Wilson, 2008; Fang, 2010; Hyman, 2009; Liang et al., 2004; Oxman-Martinez et al., 2005; Sanmartin \& Ross, 2006; Wood \& Newbold, 2012). Immigrants may have difficulty in accessing healthcare due to their inability to speak adequate English or French, especially for older adult immigrants (Chinese Advisory Council [CAC], 2008; Guruge et al., 2009; Liang et al., 2004). Furthermore, women are often migrating as dependents or sponsored spouses, which can limit their ability to seek healthcare because of perceived burdens to their sponsor (Caulford \& D'Andrade, 2012). Yet the heterogeneity of immigrant women requires examining their health in a way that accounts for possible differences. The social determinants of health can be a way to account for this heterogeneity among immigrant women (Atlantic Centre of Excellence for Women's Health [ACEWH], 1998; Guruge et al., 2009). Interrelationships between many factors (i.e., ethnicity, age, sex, geographic location, immigrant status, socioeconomic status, housing status) may influence health as social determinants (ACEWH, 1998; Newbold, 2005). While studies were completed about immigrant health (ACEWH, 1998; Lou \& Beaujot, 2005; Sanmartin \& Ross, 2006; Vissandjee et al., 2001; Wood \& Newbold, 2012), health outcomes for specific ethnic groups, older adults or women 
are fewer (ACEWH, 1998; Hyman, 2007; McMaster Research Centre for the Promotion of Women's Health, 1999; Wang \& Hu, 2013). The reasons for studying older immigrants, older Chinese persons, and Chinese immigrant women are outlined below.

Older immigrants have different characteristics than the general Canadian population. Older immigrants are more likely to reside in Toronto or Vancouver than non-immigrants: in $2001,30.4 \%$ of older immigrants lived in Toronto compared to only $7.4 \%$ of Canadian-born older adults (Statistics Canada, 2007). The total population of women aged 65 and over in 2006 was $14 \%$ compared to $20 \%$ of the immigrant women population (Milan \& Vezina, 2010 ). Older immigrant women were more likely than the non-immigrant population to live with relatives at almost $13 \%$ ( $5 \%$ of non-immigrants), as well as older immigrant men at $3.4 \%$ ( $2.3 \%$ of nonimmigrants; Milan \& Vezina, 2010).

Older immigrants, such as older Chinese adults could benefit from further study since a large proportion of older Chinese adults are immigrants (CAC, 2008; Lam, 1994). In a Chinese community report in a Greater Toronto region, two of the top five needs and challenges for the community were language barriers and supports for older adults (CAC, 2008). Older Chinese adults also faced barriers of transportation, cultural differences and isolation (CAC, 2008; Lam, 1994). It is noted that in one study that asked older Chinese immigrants about the barriers they faced in healthcare access, health system factors (administrative or professionals) accounted for about $33 \%$ of the variance compared to sociodemographic or personal factors, which accounted for about $29 \%$ of the variance (Lai \& Chau, 2007).

Past research showed that compared to immigrant men, immigrant women have poorer outcomes in physical health and mental health studies, which is a concern for Canadian society 
(Kim et al., 2013; Wang \& Hu, 2013). This outcome has been found with studies involving

Chinese immigrant women in Canada (Kim et al., 2013; Lai, 2004; Lai \& Chau, 2007; Wang \& Hu, 2013). In a study that did not separate Chinese immigrants from Canadian-born Chinese, older Chinese Canadian women were found to be less healthy than their male counterparts (Lai, 2004). In another study, Chinese immigrant women were over three times more likely to report an unhealthy status than Chinese males in a comparison with overall foreign-born, South Asian, and Portuguese immigrant groups (Wang \& Hu, 2013). Another study found that Chinese immigrant women are among other groups of immigrant women that are more at risk for poor health (Kim et al., 2013). Older Chinese immigrant women were also found to be more vulnerable to experiencing service barriers in healthcare (Lai \& Chau, 2007). However, these studies were unable to pinpoint demographic or social factors that may influence reports of poor health for Chinese immigrant women. As such, a study is needed to examine the social context that contributes to the health experiences of older Chinese immigrant women.

\subsection{Research Purpose}

Although other studies have found social factors that are important to other immigrant women's health, it is unknown to what extent these factors are important for Chinese immigrant women (Kushniryk, Titus-Roberts \& Wertz, 2014; Lou \& Beaujot, 2005; Meadows, Thurston \& Melton, 2001). Older Chinese immigrant women face potential health challenges in addition to aging (Chundamala, Matsuo \& Peng, 2006; Liang et al., 2004; Todd \& HoffmanGoetz, 2011). Cultural issues surrounding health may impact older Chinese immigrant women's health practices (Liang et al., 2004; Todd \& Hoffman-Goetz, 2011). Although Western medicine separates physical health and mental health, the body and mind are viewed holistically in 
Chinese medicine (Chen, Kazanjian \& Wong, 2009; Fang, 2010). Due to stigma about mental health problems in Chinese culture, subsequently mental health issues may be presented as physical health issues (Chen, Kazanjian \& Wong, 2009; Fang, 2010; Saechao et al., 2012). Therefore, it is important to probe beyond the physical health symptoms for Chinese immigrant women to understand the social context that may affect their health.

Chinese older adults may have difficulty acquiring a new language late in their life. Their lack of official language skills, together with increased health problems that can be linked to aging leaves older immigrants at risk of not obtaining adequate healthcare. A research gap exists when researchers fail to use immigrants' primary language to ask about their experiences with physical health or mental health services if immigrants lack official language skills (ACEWH, 1998; Kushniryk, Titus-Roberts \& Wertz, 2014). Older Chinese immigrant women, in particular, may not have had the opportunity to learn another language, or in some cases obtain an education (Anderson, Blue \& Lau, 1991).

The evidence about older Chinese immigrant women's health, so far, points to a need for further research into the effects of social determinants on their health (Chundamala, Matsuo \& Peng, 2006; Hyman, 2007; Kim et al., 2013; Lai, 2004; Lai \& Chau, 2007; Wang \& Hu, 2013). To address language barriers and to understand the social context of older Chinese immigrant women, this project aimed for a better understanding of their experiences with health and the healthcare system through semi-structured qualitative interviews that were conducted in Cantonese with older Chinese immigrant women. In addition, service providers that work directly with the population of interest were interviewed about issues that their clients encountered. This paper will elucidate the varied health experiences of Chinese 
immigrant women and expand research knowledge about the social context of a less extensively studied group, older Chinese immigrant women.

\subsection{Literature Review}

\subsubsection{Historical Context of Chinese Women in Canada}

Cantonese-speaking women have a longer history with Canada since their husbands or sons from southern China worked on the railways or mines in Canada from the late 1800s. However, Chinese women could not migrate until after the 1947 Chinese Exclusion Act, which was enacted by the federal government, was repealed. Therefore it was not until the 1960s when family reunification was allowed that more substantial numbers of Chinese women arrived in Canada (Das Gupta, 2000). The balance of Chinese immigrant women to men was achieved with approximately 52\% Chinese female immigrants between 1980-2000 (Wang \& Lo, 2005). The majority of Cantonese-speaking immigrants arrived before 1997 when Hong Kong was returned to China, while more recent Chinese immigrants are Mandarin-speaking (Wang \& Lo, 2005).

However, it is important to note that recent Chinese immigrants in Canada have a more diversified geographic and linguistic background than previous waves, including ethnic Chinese from Taiwan, Southeast Asia, and South America (Wan, 2004). Educational and economic backgrounds are also diversified, so while recent Chinese immigrants share the same ethnicity, their sociodemographic profiles vary. Yet recently immigrated, older Chinese women share an immigration status that is similar to other Chinese immigrant women in that they are likely sponsored or dependents (Poy, 2013; Preston \& Man, 1999). This dependency on their sponsor can affect their access to healthcare (Oxman-Martinez et al., 2005; Wang, 1997). 


\subsubsection{Toronto's Chinese Community}

Toronto is one of the most culturally diverse cities in the world, with over 200 distinct ethnic origins identified in the 2006 census (City of Toronto, 2015). Almost half of Toronto's population was born outside of Canada at approximately 1.2 million out of 2.8 million (City of Toronto, 2015). The Chinese are among the top five racialized groups in Toronto at $11.4 \%$ or approximately 283,000 people in 2006 (City of Toronto, 2015). Toronto is home to the largest population of Chinese in Canada by metropolitan area (approx. 537,000 ), however it is second to Vancouver in terms of proportion of the population $(9.6 \%$ compared to $18 \%$; Statistics Canada, 2006). Approximately 420,000 people in 2006 spoke Chinese as a mother tongue language in Toronto, consisting of two-thirds identifying Cantonese and one-third identifying Mandarin (City of Toronto, 2015).

Many Chinese immigrants choose to immigrate to Toronto for employment opportunities or for its large established Chinese ethnic community (Wan, 2004). This echoes results from a study of Hong Kong immigrants to Toronto (Preston, Kobayashi \& Siemiatycki, 2006): $37 \%$ immigrated as skilled workers and approximately one-third immigrated through family sponsorship. Two-thirds of participants stated the presence of other family members as the main reason for migrating (Preston, Kobayashi \& Siemiatycki, 2006).

\subsubsection{Social Determinants of Health}

A number of social factors were identified that could influence Chinese women's health, immigrant health, or women's health. Factors found to be relevant for Chinese people or Chinese women will be described first, followed by factors found to be important for other immigrant women. In one study among older Chinese adults, sociodemographic variables such 
as being female, being single, being an immigrant from Hong Kong, having a lower income, and living in Canada for less time were predictors of more health service barriers (Lai \& Chau, 2007). In another study, age and income were significant risk factors for reporting poor health, especially for low-income, elderly, married females (Wang \& Hu, 2013). Married or commonlaw Chinese immigrants were more likely than single immigrants to report poor health, which meant that married Chinese female immigrants were more vulnerable for health deterioration (Wang \& Hu, 2013).

Chinese health beliefs could influence the use of the Canadian medical system for Chinese immigrant women. Chinese people usually perceive mental illnesses as "organic disorders," which can explain the expression of psychological problems in a psychosomatic form (Fang, 2010, p. 71). As such, Chinese patients are more likely to consult their family doctors rather than seeking help from mental health professionals. This may also explain why patients who have a doctor that speaks their language are less likely to use mental health services (Chen, 2010). Yet, even doctors who speak the same language and share the same culture often fail to recognize and treat their patients' mental health issues (Fang, 2010). In addition, Chinese patients may use traditional Chinese medical practitioners for relief from emotional difficulties (i.e., herbalists, acupuncturists; Fang, 2010; Lam, 1994). Moreover, the concept of mental health for immigrant women can be heterogeneous and may not conform to Western mental health beliefs (Wong \& Tsang, 2004). Different health beliefs also impacted the dietary behaviours of Chinese immigrants to Canada (Kwok et al., 2009), and their use of prescription drugs (Morgan et al., 2011). These cultural aspects can influence the health behaviours of Chinese immigrant women in Canada. 
Social class was noted as a factor that can affect Chinese women's mental health in Canada, however in Tang, Oatley and Toner's (2007) study, they did not compare different social classes of Chinese women. The role of social class in health has not been extensively studied for Chinese immigrant women so far, although studies have noted differences in health maintenance and in health promotion (Calnan, 1986), and self-reported health status (Borrell et al., 2004) between different social classes of women. One study (Anderson, Blue \& Lau, 1991) did note that the impact of social class might influence a doctor-patient relationship. A Chinese immigrant woman consulted a doctor that spoke the same language and came from the same culture, yet she felt that there was a lack of understanding from the doctor for her workingclass situation in managing diabetes. As such, the role of social class as a factor needs further exploration in relation to Chinese immigrant women's health.

Family members could influence the decisions surrounding women's health (Fang, 2010; Kushniryk, Titus-Roberts \& Wertz, 2014). Women did not wish to disrupt relations with the person who sponsored them, who was responsible for their health costs, as such they refused to seek medical treatment unless absolutely necessary (ACEWH, 1998; Wang, 1997). Chinese immigrant women who depended on their husband or friends to translate during visits to the doctor felt demoralized and embarrassed over this dependence (Wang, 1997). However, they also felt that doctors contributed to these feelings by ignoring them during the appointment and focusing on the translator (Wang, 1997). Consequently, dependence or family may influence Chinese immigrant women's health behaviours.

More broadly, spirituality and religion could affect immigrant women's health. For some immigrant women, it was a vital health maintenance practice that provided nurturing and 
relaxation (Meadows, Thurston \& Melton, 2001). The authors noted that it was through asking immigrant women about everyday practices in their life rather than specific mental, spiritual, and social factors that these discussions occurred (Meadows, Thurston \& Melton, 2001). Discussions about stress, emotional trauma, and abuse were situated in discussions of family history, the experience of immigration, everyday practices, and the use of health resources (Meadows, Thurston \& Melton, 2001). As a result, spirituality and religion is a factor that may influence the health of immigrant women.

Social support and a sense of belonging could influence immigrant health. It was theorized by Lou and Beaujot (2005) that if immigrants received as much social support (i.e., coping resources) as the Canadian population, their healthy immigrant advantage would be more evident. The Canadian-born population received more social support in general than recent or long-term immigrants in the Canadian Community Health Survey. Social support was significantly associated with self-rated mental health. Long-term immigrants and immigrant women were more likely to suffer from poor mental health, but were less likely to use mental health resources than Canadians. Immigrant women were more at risk of poor integration into Canadian society since they had fewer opportunities to learn languages and skills, or to be employed (Lou \& Beaujot, 2005). These findings show that social support and a sense of belonging should be considered as a factor that may influence the health for Chinese immigrant women.

Neighbourhood context could be another factor that affects Chinese immigrants' health. Immigrants that ranked their health as poor or fair were more likely to live in areas of ethnic concentration, however this was not significant for the four immigrant groups featured in one 
study, which included the Chinese (Wang \& Hu, 2013). In the same study, respondents were more likely to rank their health as poor or fair if they experienced neighbourhood material deprivation (i.e., lack of access to transportation, limited proximity of grocery stores and community resources), however it may not apply to all immigrants (Wang \& $\mathrm{Hu}, 2013$ ). The neighbourhood context may also differ in Toronto compared to other regions with smaller Chinese populations in Canada.

Therefore, there is evidence that social context factors such as sociodemographic characteristics (Lai \& Chau, 2007; Wang \& Hu, 2013), cultural health beliefs (Chen, 2010; Fang, 2010; Lam, 1994; Lu et al., 2008), doctor-patient relationships or social class (Anderson, Blue \& Lau, 1991), and familial influence (ACEWH, 1998; Kushniryk, Titus-Roberts \& Wertz, 2014; Wang, 1997) can affect Chinese immigrant women's health status and health behaviours. There may be relationships between neighbourhood context, social support, sense of belonging, and spirituality to influence the health of Chinese immigrant women, which was found with other immigrant women or immigrant populations. These factors will be explored through responses to interview questions in subsequent sections of this paper. Through interviewing Cantonese-speaking older immigrant women, relevant social factors that influence their health and healthcare experiences will be identified.

\subsection{Theoretical Framework}

\subsubsection{Intersectionality Theory}

Intersectionality was a term that began with American critical race scholar Kimberlé Williams Crenshaw (1989). Intersectional analyses in the health context examine intersections

of gender, ethnicity, social class and other areas of difference (Collins \& Guruge, 2008). Humans 
cannot be reduced to single social categories, nor are they a sum of additive independent effects (Hankivsky, 2014). Gender is experienced differently according to the social context, and depends on historical, socioeconomic, and cultural experiences (Crenshaw, 1991; Ng, 1988). Some feminist and antiracist discourses failed to account for intersectional identities that racialized women represent, thereby marginalizing racialized women within both perspectives (Crenshaw, 1991). Ng (1988) noted that treating immigrant women as one homogenous group ignores differences of education, class, and social position in society. The goal of intersectionality is to highlight that groups such as Chinese immigrant women should not be treated as one homogeneous group (Hankivsky et al., 2010). Intersectionality aims to explore differences among groups and find the effects of interacting social factors (Hankivsky et al., 2010).

Social determinants of health are social and economic conditions that impact the health of individuals, families, and communities (Collins \& Guruge, 2008). Immigration status, along with other social determinants including social isolation, language barriers, separation from family, change in family roles and norms, and unemployment are significant factors that can negatively influence the health of immigrants and refugees (Fowler, 1998). Moreover, some immigrant women are disadvantaged by age, poverty, and discrimination (Preston et al., 2013). Increased international efforts to understand health holistically recognizes that social, cultural, economic, and physical circumstances can be even more important than personal health behaviours to affect an individual's health (Raphael, 2009).

However to focus on the systemic barriers influencing immigrant women, the larger social structures behind social determinants of health need to be considered. For example, 
unemployment, stress and unsafe work conditions, and barriers to affordable care are associated with poorer health (Public Health Agency of Canada, 2011). The process behind unemployment for immigrant women involves barriers by employers and professional associations. They discount foreign education from certain countries (Teelucksingh \& Galabuzi, 2005), or create a double disadvantage of not recognizing foreign credentials or work experience, and insistence of Canadian work experience (Dlamini, Anucha \& Wolfe, 2012). These barriers that are in place by employers are a form of discrimination that leads to unemployment for immigrant women. These barriers have been linked to anti-racist frameworks since it perpetuates societal ideology and constructs boundaries that if it is not Canadian or Western, it is considered inferior (Collins \& Guruge, 2008; Satzewich \& Liodakis, 2010). Therefore, while social determinants of health identify factors that influence immigrant women's health, there is also a need to examine the structural barriers behind those factors, and requires a larger, encompassing framework such as intersectionality to examine social justice issues.

There is not a single way to perform intersectional analysis of research data, however social and historical context must continue to inform the analysis (Hunting, 2014). Intersectional analyses focuses on the interactions of different social locations, systems and processes; investigates rather than assumes the significance of any specific combination of factors (Hankivsky, 2014). Due to limited space in this MRP, an exhaustive intersectional approach will not be used since the numerous themes in the interviews are also important. I have concentrated on intersections that are the most salient in the intersectional analyses.

The health experiences of older Chinese immigrant women are varied and cannot be 
defined as a group due to different social contexts. The responses revealed that the social context is more salient among factors that overlap and that there is heterogeneity in the women interviewed, which makes this theoretical approach relevant.

\section{Methodology}

\subsection{Research Questions and Ethics}

The purpose of the study is to understand Cantonese-speaking older immigrant women's perceptions of health, their social context, and their experiences with health and the healthcare system since immigrating to Toronto. The main research question is: How do Cantonese-speaking older immigrant women perceive and experience health and healthcare services in Toronto? A sub-research question: How does social context influence their health experience?

I will be using a qualitative, interpretive method to answer these research questions since the aim of the interpretive method is to understand and describe meaning that is socially constructed by group members (Neuman, 2006). This method is related to the intersectional theory since it allows an examination of the many possible meanings that intersect and are socially constructed by Chinese immigrant women. The interpretive method also explores conditions that disadvantage and exclude individuals or cultures in our society, which is relevant for Chinese immigrant women (Creswell, 2007).

Since this research design involved interactions with human beings, ethical approval was obtained under the merits of the Tri-Council Policy Statement: Ethical Conduct for Research Involving Human Beings (TCPS) by the Research Ethics Board at Ryerson University. The primary ethical concerns included the emotional discomfort that some might feel about discussing their 
personal lives, the voluntary nature of their participation, and the confidentiality of their information.

As a researcher using the intersectional analytical approach, reflecting on the social location between the participants and myself is a necessary process. Although I do have the power of the written word and fluency in English, my goal is to use my power to add my voice on their behalf for the Chinese community. I am not privileged by education in comparison to my participants. Both of the Cantonese-speaking women have university degrees, and the community workers also have at least post-secondary degrees. All of my participants were women. In addition, the participants and I were all ethnically Chinese, which allows us to have the same ethnic group identification. In sharing the same ethnic group, I must follow Chinese etiquette with regards to age. Since I am younger than the Cantonese-speaking participants of my study, it was expected that I would be respectful and address them as "Mrs. (last name)," regardless of their first name. My Cantonese language skills were not at an advanced level compared to the Cantonese-speaking women, so they had a language advantage. I was privileged as an in-group member among the Cantonese-speaking women and Chinese community workers that they all wished to contribute to my research. Nevertheless, it is important to keep in mind that without a personal relationship to the Cantonese-speaking participants, they will not talk as openly about certain aspects of their lives since that is usually the Chinese social norm.

Despite the fact that my project was conducted from an academic institution, this did not privilege me when attempting to access Chinese older adults through community organizations. Many community organizations in Toronto refused to allow me access to their 
vulnerable older adult participants for the recruitment purposes of my project. I wondered about the relationships between academics and community organizations for this to be an issue. Have other academics damaged a potential, mutually beneficial partnership? Or are community organizations simply too busy to accommodate academic requests?

I acknowledge that the challenge of structural barriers may make my participants uncomfortable for having their words interpreted in this critical context. However, this study could potentially help highlight that some changes are needed in the healthcare system for Cantonese-speaking older immigrant women, and for the Chinese immigrant community in general.

\subsection{Participants and Recruitment}

The study criteria for recruitment outlined that potential Cantonese-speaking participants must be women aged 50 or over, have limited or no English language skills, and migrated to Canada within the past 10 years. The reasons for this criteria were because women with no or limited English language skills may be placed in a more difficult situation when they try to access healthcare, and will likely rely on someone else to help them. The age criteria was chosen after surveying studies with Chinese immigrant women that used ages 50 and over (Liang et al., 2004; Todd \& Hoffman-Goetz, 2011), studies that included a wider range of 25-60

(Tang, Oatley \& Toner, 2007; Wang, 1997) and studies that used 55 or 65 as the minimum (Lam, 1994; Lai \& Chau, 2007). Ages 50 and over would allow a good overlap of ages in the current study compared to other studies, and also would focus on women who may have more health issues. Older adult programs with community organizations are also available starting at age 55. The migration criteria was chosen since this is used by Statistics Canada's Canadian Community 
Health Survey to separate recent immigrants from long-term immigrants in their survey data (Gee, Kobayashi \& Prus, 2004; Wang \& Hu, 2013).

The women were recruited from Toronto-area community centres and immigrant settlement organizations through identifying relevant organizations and potential contacts. Flyers were posted in Traditional Chinese (written form of Cantonese language) at participating community centres and organizations. However, only two women shared their experiences through this recruitment process. Therefore, the study was expanded to include Toronto-area community workers that interact with this population of interest on a regular basis to gain a better understanding of ongoing needs and issues.

Community workers were recruited through purposive sampling of community organizations that have programs that serve mainly Chinese clients in a health-related capacity. Community workers were identified through community organization websites and their availability during the research period. Three community workers were interviewed, however one withdrew their participation after being interviewed since her manager did not give approval before the study deadline. Two community workers remained in the analysis phase. All participants received an honorarium of $\$ 20$ to participate in this study.

\subsection{Data Collection}

All interviews were conducted in a semi-structured format in-person and audiorecorded. The interviews were conducted over an eleven-week time span. The Cantonesespeaking older immigrant women were interviewed for approximately 2 hours, while the community workers were interviewed for approximately 1 hour. For Cantonese-speaking older immigrant women, the interview questions focused on demographics, social context, and 
health experiences. A few example questions included: What was your experience like immigrating to Canada? What is your understanding about health? How has your health been since immigrating to Canada? Interviews were conducted in Cantonese and transcripts were translated back into English. Random sections of the translated transcripts were checked with a friend who is bilingual in Cantonese and English. The consent form was translated into Traditional Chinese for the understanding of the Cantonese-speaking women. A list of health, counseling, and settlement agencies for Chinese immigrant women in Toronto was also provided to participants.

For the community workers, interview questions involved the problems that their clients face, attitudes towards Traditional Chinese medicine from their clients, and stigmas that can impact help-seeking behaviours, among other areas. Example interview questions included: Why did their organization decide to help Chinese access physical health or mental health services? Who is their typical client (i.e., age, gender, socioeconomic status, family status)? What is the most common problem that they help Chinese older adults with? Interviews with community workers were conducted in English. These interviews were transcribed verbatim.

\section{Data Analysis}

The data analysis of the interview transcripts was based upon a guide for content analysis of qualitative data (Taylor-Powell \& Renner, 2003). An emergent strategy can be used to identify themes. Transcripts are read through and themes or issues that recur in the data are identified, which become coding categories. Categories may be organized into larger, main categories and smaller, subcategories. While some data fit into mutually exclusive categories, some sections of data fit into two or more categories. Data is then sorted into their categories 
to identify patterns and to bring meaning to the responses. Interpretation occurs through attaching meaning and significance to the analysis (Taylor-Powell \& Renner, 2003).

The themes uncovered through an interpretive perspective will be thoroughly discussed in this chapter. Participant characteristics will first be described, followed by participant answers to the main research question and themes emerging from the sub-research question will be explored. The intersectional analyses will be the focus of the Discussion chapter.

It should be noted that when possible, information pertaining to specific groups was used (i.e., Chinese immigrant women), however this was not always possible since the community workers do not only work with Chinese immigrant women. In this paper, ethnicity refers to ancestral origins, while culture refers to social process and practices that can be linked to ethnicity but may differ due to other social categories (Satzewich \& Liodakis, 2010). Western medicine refers to the biomedical model (Lu et al., 2008). While I recognize that mental health might be an application of a Western medical term upon a cultural group that does not think of the mind and body as separate, for the clarity of this paper I will use the term. Also, efforts were made to specify between physical and mental health, however when the general term health is used, it refers to both.

\subsection{Participant Characteristics}

The two Cantonese-speaking older immigrant women were both from Guangzhou, China. Participant 1001 is 71 years old, completed a university degree in chemistry and worked in research. She is married with 2 middle-aged adult children, has permanent residency status and has lived in Canada for 7 years. Participant 1002 is 69 years old, earned a university degree in mechanical engineering and worked as a senior engineer. She is divorced, has 2 middle-aged 
adult children, has permanent residency status and has lived in Canada for 2 years. Both women took Language Instruction for Newcomers to Canada (LINC) classes to improve their English.

The two community workers were approximately 45 years old and possessed at least a post-secondary degree. Participant 1003 is a senior mental health worker with 16 years of experience working in the settlement or mental health area, obtained a post-graduate diploma in management and a Bachelor's degree in Social Work. Participant 1005 is a health promoter with 14 years of experience working in the health area, and a Master's degree in Public Health. They both work with different groups of Chinese clients: women, older adults, young mothers and have experience with non-Chinese clients.

\subsection{Perceptions of Health}

To explore the participants' perceptions of health, three questions were asked: Who is a healthy person? How would you describe a healthy person? What were their experiences with healthcare services? The healthcare services were not limited to medical doctors, but also included other health professionals that older adults might need such as dentists, optometrists, chiropractors or physiotherapists.

The Cantonese-speaking women perceived health holistically, and as important to function in everyday life. "Health means no illness, good well-being physically and emotionally. Sleep and have meals at a regular time. Being well-rested is needed to have energy to pay attention for English class" (Participant 1001). "I feel that mental, heart, emotional health and wellness being is very important. I am able to sleep, able to walk, to work on my own" (Participant 1002). 
A healthy person took into account two principles: "First is to exercise. Second is not to indulge in drinking and eating. Simple is the best policy" (Participant 1001). Ensuring that food had nutritional value and doing everyday household tasks were also important to the participants.

The Cantonese-speaking women's experiences with various medical professionals differed. Both preferred to find doctors in Toronto that could speak Cantonese, and interacted with health professionals that spoke Cantonese. They both experienced instances of their doctors not investigating their medical problems further.

We do have one, but our family doctor won't take care of this. Family doctors have so many patients and each time we see them, it only takes 10 minutes to be finished. [... ] My family doctor has a lot of patients, he doesn't want to investigate and he has no time for me. [... ] I went twice [to the hospital]. If you have an appointment, it's probably faster. But if you go on your own to the emergency, then it takes long. That time it was a Sunday and the family doctor was not there. So I had a nose bleed and didn't know what was wrong. I walked there to the hospital to get it checked but next time, I would not go (Participant 1001).

I have a family doctor who is from Hong Kong, speaks English and Chinese, he is young. The first one was older and he knew Cantonese and English and he seemed fine. But I don't know, he didn't want to investigate for me. I wanted to know so I changed to a new one. He is much clearer. These were not in the hospital, this was in a clinic (Participant 1002).

Both understood the need for medical testing every year and felt that they had no 
problems since some interpretation services were available. "Some of the departments speak Chinese. Some departments don't. Most of the time, they arrange [for] someone who speaks Chinese to talk to me" (Participant 1002). Participant 1002 also saw a physiotherapist that was from Hong Kong for her shoulder and knees. She found the experience helpful to "correct her old habits."

Pharmacists were appreciated for their role in taking the time to explain the drugs to them.

There are some pharmacies that have someone who can speak Cantonese. I think the pharmacists explained it more clearly. This drug will cure this illness, and this is how you take it, don't do this or that. The family doctor didn't say any of this. They don't have time to say this. So I think the pharmacists have better communication than the doctor (Participant 1001).

Although both women took care of their teeth, they found dentists in Canada to be too expensive. Thus, they found other ways to access dental care. "Yes, every time I go back to China I will go for a dental checkup. I go to take care of my teeth well and clean my teeth well. Here [in Canada] it's too expensive" (Participant 1001).

Yes, in Canada, I went to clean my teeth. [. . .] The dentist is close to where I lived. Teeth are very important. They speak Chinese, they are students. They charge $\$ 30$ per visit ... Every step of the way, they stop and let the instructor check before they move on to the next step (Participant 1002).

The Cantonese-speaking women were able to find Cantonese-speaking doctors and other health professionals to provide them with healthcare services in Toronto. Since the 
community workers do not only work with Chinese immigrant women, their responses were for their clients' general experiences. In comparison to the Cantonese-speaking women, the community workers emphasized language among other issues that caused difficulties for Chinese immigrant clients to access healthcare.

I think that although in Canada we always say that it's a human right, everyone can access to different systems, but in the system they have already the barriers. If you don't have language ability, you can't access the services directly. That's why [organization] was established in 1982, because we want to fill in this service gap [in mental health services]. [. . .] Especially I would say that their cultural competence. Even though they can speak English, if they want to seek help, they would.. Just like if you talk to your family doctor, most people will find their own language, Chinese-speaking family doctor instead of the English-speaking person (Participant 1003).

Certainly language and physical challenges. [. . .] So first, language is the first issue. If you don't understand, you cannot do anything. Then physical, something they can learn. Chinese, not many of them use walkers or accessibility devices, but they need to know how to use that properly. And physically they are old, they are not turning around that quick (Participant 1005).

Further evidence of language issues and other post-migration challenges or systemic barriers are explored in the next section.

\subsection{Social Determinants of Health}

The sub-research question is how does social context influence Cantonese-speaking older women's health experiences? The social context involves examining the social 
determinants of health, which includes personal characteristics or structural barriers that influence health. The main themes to answer this question were divided into systemic barriers and post-migration challenges. The main themes have subthemes that further elaborate on the main theme. Subthemes were matched to the post-migration challenge main theme according to the degree of agency an individual has within that subtheme. While keeping the length of this paper in mind, I aimed to allow participants to describe what we are trying to understand in their own words. Attempts were made to summarize participant responses to each theme, but their own words best described what I would like to convey for them. The community workers who work with this population on a regular basis often do not get a chance to talk about their clients. Their responses are unique and valuable, and I would like to keep most of their quotes intact since most research that I read did not cover these topics in much detail.

\subsubsection{Post-migration Challenges}

Immigration is a significant life event for most people, whether it is their own choice or their family's choice. There are many factors that may make adjustment to the receiving country better or worse. Some of these factors become post-migration challenges that immigrants must negotiate with a degree of agency and were identified in the interviews with the participants. The factors presented here are subthemes and include: language learning, immigration experience, social isolation, geographic location, socioeconomic status, family issues and different health beliefs. Each subtheme is related to other subthemes.

\subsubsection{Language Learning}

Learning a new language can be difficult, especially at an older age (CAC, 2008; Guruge et al., 2009; Liang et al., 2004). Both Cantonese-speaking women were fortunate to have 
learned some English in China but were not used to speaking the language every day. Despite having an adequate knowledge of English, Participant 1001 told me that she was unable to navigate Ryerson University's telephone system to contact me for the research study. She managed to email me instead. Her comments made me realize that often such details will go unnoticed. Even though both women have LINC Level 5 English, they were unable to feel at ease with going to doctors who only spoke English. Participant 1001 reiterated several times in our interview about her worry and anxiety about having to see an English-speaking doctor unexpectedly.

So when we see a doctor, language is the problem. ... But the medical terms, how to explain to the doctor where? For example, pain has a few levels: ordinary pain, sharp pain, acute pain etc. I find communication with the doctors is difficult for me. [. . .] I have to look up the dictionary the night before I go to see the doctor. Then I go there and say what I looked up. But what the doctor says I don't always understand and I don't have the dictionary or computer with me, so what words are these? Every time we go to the hospital, we know it will be difficult (Participant 1001).

Participant 1002 also prepares before her doctor visits: "I can communicate in English with my family doctor who is not Chinese. I first prepare beforehand by writing out things before my visit with my doctor. [. . . I can still speak some English or listen to some but it is slower. The previous family doctor was very patient with me. He spoke English very slowly to me. Others are not so patient. It sounded like I was taking English class."

If a doctor is rushed to see patients in limited amounts of time, they will not have the 
tolerance to explain to the patient in simple terms about the medical problem. Therefore, it is also healthcare professionals who have a role in addressing language issues of their patients. The women attempted to prepare for what they wanted to say before a doctor's visit, but they could not prepare for what the doctor will say or for further questions during the visit.

The community workers stated that recent immigrants were not the only ones who needed language help with accessing health services. Immigrant women that arrived at a younger age and have lived in Canada for a while may also need help if they did not have the time to learn English while working to support their families.

There are a lot of Chinese and Vietnamese. They can't find services because of the language barrier [. . . ] Some of them also come to Canada for over ten years, but they prefer to speak in Cantonese or Mandarin, seldom to speak in English. When they go to the social circles, still they speak Cantonese and Mandarin (Participant 1003).

But older immigrant women, who have been here for many years, they worked their whole lifetime, either in the garment factory because I know a couple of them [that] said that to me. That's the reason why they don't speak English even if they have been here for 40 years (Participant 1005).

Learning a language is a post-migration challenge because the decision to learn a new language also signifies migration from one country to another as a long-term decision. Immigration is a long process, and can be another challenging experience for newcomers, which is examined in the next section.

\subsubsection{Immigration Experience}

According to the two Cantonese-speaking women participants, their physical health was 
not significantly affected by the immigration experience. In fact, Participant 1002 mentioned that the air quality in Canada was much better than in China, which was better for her physical health. In comparison, they spoke indirectly about immigration having more of an effect on their mental health. Immigration itself can be stressful, but what about the social context surrounding a person's preparations before and after? The social context can affect a person's psychological adjustment to their new country.

The Cantonese-speaking women participants were both sponsored by their adult children to immigrate to Canada. They both visited their adult children in Canada prior to applying for immigration to Canada and felt that they somewhat knew what to expect following migration. However, both faced difficulties during and after immigrating to Canada. One woman faced a long application process and family disruption, which was partially due to immigration.

It took well over 3.5 years for my application to go through the process. [. . .] Originally my daughter tried to sponsor both of us - her mother and father, but then she changed it to only one. So it is not welcoming us and it is not good. ... Originally, my daughter is the one who thought they probably think how can I support 2 parents, so let's cancel one first. So we cancelled her father's, and originally he was going to come too. [. . .] I had to file separation papers with my husband, since he did not want to come to Canada (Participant 1002).

Although the participant did not further explain about circumstances surrounding her and her husband's separation, the fact that her daughter had to choose only one parent to sponsor may have played a role in their separation. Consequently, immigration was not only an 
adjustment of different countries' systems and cultures; it was an adjustment of family life for this participant. After being married for over 40 years, she now found herself separated from her husband in a new country.

The other Cantonese-speaking woman experienced difficulties after arriving because her adult daughter sponsored them to immigrate to Canada, but was asked by her employer to work in the United States for three years. Thus, adjustment to Canada after immigration was left solely to her and her husband, including finding low-cost housing.

At first it was hard. When we first came in May 2009, my daughter was commissioned by her employer to the United States in July 2009. She had to work in the U.S. We bought a round trip plane ticket thinking of going back to China because I did not know anyone here in Canada. Lots of people persuaded us to stay in Toronto because it was a good place to live. [. . .] We put our application in June 2009 . . . We lived in a coworker's place. There was no interview or anything. In August, [they] asked if we wanted to see the older adult's apartment. I said we don't need to see it, we will take it. We decided not to go to see as we accepted any type of home because we were 'homeless.' We don't have a choice. They said we could take a look, but I said just give us the keys. [. . . ] People ask me and I say the difficult part has already passed, so now it's considered very good (Participant 1001).

The community workers who participated in the study also highlighted the hardships of Chinese immigrants. Although Chinese from Hong Kong are ethnically similar to those from Mainland China, they vary in language and in their reasons for migrating. Those from Hong Kong usually speak Cantonese, and migrated pre-1997 to avoid political instability. One 
community worker stated that migration is a long-term process, which also will influence how Canadian society views them as immigrants.

Most of the people before 1997 [immigrated] because of the political reasons, for educational and other reasons. Most of the Cantonese community arrived, immigrated before 1997. After that the pace of immigration process seemed to slow down. That's why in the past ten years, most of the people came from Mainland China and other ethnic groups, Koreans or Filipinos. Yeah, that's why our Cantonese community is well established in Toronto, but I always say that migration is long term. It's not just ok, you come and then you can settle. We still have from day one when they immigrate, their status is still immigrant. They can't change this, it's not like [being] born in Canada. [. . .] Our target group I can see that $99 \%$ are immigrants. They are not born here (Participant 1003).

Another community worker told me that some Chinese older adults described their circumstances as an "overseas prison." A word that was derived from the Cultural Revolution in China in the 1970s when young persons were sent for hard farm work (插隊 or 插队) has now been used to describe older persons being sent overseas for hard work (洋插队). In addition, she highlighted the fact that numerous family visitors supported their children and the Canadian economy by performing unpaid labour such as childcare. This is in contrast to attitudes from government officials that family class immigrants do not contribute to the Canadian economy (Preston et al., 2013).

Then we have some seniors, they are on a visitor's visa, visiting friends or family. ... They are doing labour, not a paid job. That means they are raising their grandchildren 
for no pay or taking care of the families. Some of the seniors say they are providing the quality labour for the Canadian economy and nobody noticed. We know about it, but policy-wise they think they are a burden. We like to bring that issue there, because they really raise that issue. We [visitors] are providing you guys quality labour and we're doing all chores without pay. We don't use your system. Because when they come, they have to buy their healthcare insurance, right? So it's not that they are consuming our system, indeed they have to pay quite a lot in order to stay. [. . . ] Yeah that's what they said, I'm in a prison. . . Because it used to be in revolutionary time in Mainland China, the younger one goes to the rural area right. Now it's like that bunch of people getting older, they are the ones who come to visit their younger ones that are here. They say it's reversed because you are thinking of overseas in North America is really good but actually it's another prison for them. It's called overseas prison (Participant 1005). The Cantonese-speaking women likely explained a mild version of the hardships they endured when immigrating to Canada. The community workers regularly saw the difficulties that their clients experienced, which can be the way that one is treated due to a lingering immigrant status or living in an "overseas prison." From the experiences of the Cantonesespeaking women and the community workers, there is a strong link between the role of family and immigration. Yet Chinese older adults often immigrate due to family but arrive in Canada without a social network. The role of family will be further explored in another section but older Chinese adults are vulnerable to social isolation, which will be explored in the next section. 


\subsubsection{Social Isolation}

Older adults' mental health can be affected by social isolation that they may experience in the post-migration context. Both Cantonese-speaking women had immigrated to Canada without relatives or friends other than their adult children. One participant noted if their children were not available, then this situation could create challenges in learning different ways of functioning in a new country.

In those days, there wasn't much stress or burden, but our feelings were not so good. We thought, our daughter sponsored us to immigrate but then she herself left and left us here. [. . .] At that time [after immigrating], if you wanted someone to help there was no one (Participant 1001).

The Canadian winters create even more challenges for older adult immigrants who are already experiencing social isolation. The participants who were accustomed to a warm, southern Chinese climate had to adjust to snow and ice in Canada. They were very conscious of the dangers of slipping and falling, and Participant 1002 chose to avoid going outside in the winter.

The winter lasts about 4 months. In the winter season, I mostly stayed at home and I

feel comfortable. But if I stayed home for the entire season, it is no good. [. . .] In winter, I really don't want to go out. That is not good for my health and well-being (Participant 1002).

Both women preferred to keep busy and leave the house to socialize with others.

"For me, too much time at home is not good. ... We don't like to stay at home because then we would become lazy" (Participant 1001). "I like to get out of the house for a change of 
scenery, it is better for me. [. . .] I sometimes borrow her [daughter's] bus pass. I feel better when I go out" (Participant 1002). It could be that Participant 1002 would like more social interaction as a reason for wanting to work or volunteer to get out of the house. "In Toronto, I would like to look for jobs, for full-time or part-time, \$12 per hour, or I would volunteer. I do not demand anything in return" (Participant 1002).

A community worker participant who worked directly with older adults noted that social isolation was the most common problem that they needed help with. Some older adult immigrants described being socially isolated as an "overseas prison" in the previous section. She provided them with "social medicine" and described an example of its results with one of her clients. Consequently, she enjoyed providing help to address their social isolation.

Most of our clients, they are isolated. They wanted to come out to seek help, but that's kind of a group of clients. If they are lucky to get support from our case management, that would be fine. But most of them are just isolated. [. . .] That's what he was telling me, until later on he find some people, he starts to learn English, so he went to the class and know some other seniors, then he feels better. Then the class keeps him going, so then he find us and he loves us because after the grandchildren were born he loves us. Then he comes too often. 'See I don't see my doctor, I haven't seen him for over a year.' But I said, 'you need to do your physical.' He says 'no I'm totally fine, I don't think I need it, I don't see why I was sick that time,' something like that. So I call my group, social medicine to treat seniors' isolation. .. . So I feel very good from doing that because I feel them connect and support each other, they feel energetic, that sense of belonging to each other, supporting their social net. It's so important, I thought I'm totally doing the 
right thing! It feels so good (Participant 1005).

This community worker also noticed that her Chinese clients engaged in activities according to their marital status. Married couples attended programs together, while widowers would attend programs alone. There would not be any summer programs for older non-Chinese adults, but older Chinese adults requested more summer programs.

The Cantonese-speaking women participants did not emphasize the social isolation in their lives, however they did allude to how good it felt to be outside of their house and to keep busy. Participant 1002 was especially prone to staying at home in the winter since she was not used to the different climate yet. The community worker underlined the issue of social isolation among older adults, especially the benefits derived from having a group support program in place. Older Chinese immigrant adults also may display social patterns that differ from older non-Chinese adults. The geographic location of residence may play a role in older adults' isolation. Subsequently, this factor will be explored in the next section.

\subsubsection{Geographic Location}

The geographic location of a person can sometimes be overlooked as a factor that impacts health. Yet the findings of this study highlighted that proximity to health services did impact the choice of family doctor for these Cantonese-speaking women. "My family doctor speaks Cantonese, just a 5 minute walk and we would be there" (Participant 1001). In comparison, Participant 1002 noted: "I wish it could be walking distance then it would be more convenient. I take the bus to the other clinic and transfer to another bus. It takes more than half an hour but not an hour."

Both women lived in Toronto neighbourhoods with substantial numbers of Chinese, but 
downplayed the possible benefits of having convenient access to banks or grocery stores that cater to Chinese people. It may be that they are accustomed to these services, which could be similar to circumstances in China so that they do not realize that these services may not be available in other areas of Toronto. The community worker participants also highlighted the importance of proximity in terms of the adjustments that some Chinese immigrants needed to make when living in Canada. For example, one community worker emphasized that some older Chinese adults only stayed in their neighbourhood.

The older immigrants, they have been here 50 years, 40 years, like the older senior Chinese women, but they still are bounded in Chinatown, in this area I mean. So literally, they don't know much English, don't know what is going on in the real world. They live in this neighbourhood, they've got their neighbours, they shop here (Participant 1005).

According to one of the community worker participants, some immigrants had a hard time adjusting to the suburban nature of Canadians cities in terms of managing everyday tasks. “Maybe here if you don't have driving skills, [then] maybe you are limited to your living area" (Participant 1003). This statement also becomes important when considering older Chinese adults in the Greater Toronto Area (GTA), who are more difficult to find and are likely more socially isolated. "In Toronto at least it's better, they still have TTC but if you live in GTA, I mean 905 area, you have to drive. That really, really challenges - they are really isolated. And they don't have much [social] programming either" (Participant 1005).

Older immigrants who have limited income may prefer to walk even though transit is accessible in the Toronto city area. This was highlighted by Participant 1001, who reported 
walking to the nearest hospital instead of spending money on transit fare. "I walk about an hour to St. Michael's Hospital which is far but the closest one. The other one is Toronto Eastern Hospital" (Participant 1001).

These statements demonstrated that proximity of health services could be a factor in seeking healthcare and other services. From the above discussion, socioeconomic situation also affected older immigrant women's access to healthcare, which is explored in the next section.

\subsubsection{Socioeconomic Status}

Socioeconomic status affects individuals' health choices, but the impact may be more evident for some people than others. For example, the two Cantonese-speaking women participants in this study made certain choices due to their limited finances - limited transit use, refraining from using Chinese herbalists, and choosing lower-cost options for dental services. However, overall Participant 1002 appeared to be less affected by a limited income than Participant 1001. Although Participant 1001 has a part-time job, she mentioned several times in our interview that she did not have a pension yet and needed to save money.

We have to be very exact about each dollar we spend. We have to think about whether it is important to spend it. For using transportation, we usually just walk. If we can walk there in about an hour, then we will. If we don't need to spend it, we won't. I work and get a little income, but during [school] holidays then there is no work and no income (Participant 1001).

Participant 1001 was diligent about her health, but her doctor's office charged for copies of medical reports at \$1 per page. “We don't want to spend our money for this. I also 
think that medical reports belong to the patient and they are patients' own possessions" (Participant 1001). She also noted that to transfer her records to another doctor, it would cost over $\$ 10$. She demonstrated that for those with limited income, tracking their own health through medical reports and getting a second opinion for medical advice might not be possible. Participant 1005 revealed that most older immigrant Chinese women that she knew lived in subsidized housing (apartments) in which there were health and safety concerns, among others. The older adults did not have a pension, thus relied on their adult children to support them, and subsidized housing was still costly for them. However, it is important to keep in mind that the sociodemographics of Participant 1005's service location differs from Participant 1003's service location. Participant 1003 stated that older immigrants did not always rely on their adult children. Instead among her clients, often it was older immigrants who supported their adult children financially. "Especially [with] the housing prices going up, that's why most of the people, instead of asking the children to support them, it's reverse. The parents support the children to buy the condo or house, especially the first payment" (Participant 1003).

It is possible that those who have limited incomes are also more likely in need of healthcare services. For the older adults that lived in subsidized housing, they might need to be monitored more closely for health issues linked to living in environments with poor health and safety conditions. Yet the realities of the Cantonese-speaking women and community workers' clients highlight that their individual socioeconomic situation is very much influenced by societal factors (i.e., housing costs, Canadian medical system costs) but family also played an important role. The latter is explored in the next section. 


\subsubsection{Family Issues}

Many older adults are sponsored as family class immigrants by their adult children. Dependency on family members for one's immigration status can create hardships for older adults who do not want conflicts with their adult children. Avoiding conflicts is part of saving face, which is a social rule that is valued in Chinese culture. Saving face relates to a social value that others give to a person based on their social position (Heine, 2012). Avoiding conflicts becomes a health issue when it affects the help-seeking behaviours for the health of older Chinese adults. This issue was identified in the interviews with community workers, and was also highlighted by one of the Cantonese-speaking women participants. The interviews with the women indicated that the parents tried to avoid any potential conflict with their adult children by not burdening them with their financial or health problems. For example, Participant 1001 avoided asking for money from her adult children.

My son and daughter said they would support us [her and her husband], but I don't want my son's and daughter's financial support. They have their own needs like buying a house, getting married, etc. so we don't want to use their savings. [. . .] This is something we don't talk about at our age, we don't want to be a burden to our daughter (Participant 1001).

She also did not want to live with her daughter to avoid conflicts. "Since there is a generation gap if we live together, it is easy to have conflicts with each other. That would be an embarrassment for me. If we live apart, we treat each other respectfully" (Participant 1001). It is noted that although Participant 1001 has an adult son in Toronto, she rarely spoke about him.

Avoiding conflicts meant that her and her husband were left to navigate the healthcare 
system on their own. "My children are so busy so they can't come to the doctor when we're sick, so we have to manage it ourselves without knowing the system" (Participant 1001). A community worker participant also spoke about this issue.

Or they don't know who they should turn to for support, usually it's family support but the family is not as extended as back home. They can only rely on their children and they say I feel so bad, sorry for my son - he has to take a day off to bring me to the appointment or if they have an examination or test, they [are] really scared for them. [. . .] Yeah, they feel themselves are a burden to their sons or daughters. So they feel guilty for doing that, but sometimes it's necessary, right? You need early detection [of health problems] (Participant 1005).

Many adult children (in the "sandwich generation") cannot assist their sponsored parents with timely medical care due to a combination of work demands, medical wait times, their own children and sometimes simply due to a lack of enough time in their life. Sponsored parents are then left to navigate the Canadian healthcare system on their own without the same knowledge of someone who is born in Canada or with the same language capabilities.

In contrast to avoiding conflict, the community workers also identified intergenerational conflict because of differing cultural and societal values. One community worker participant elaborated on family conflicts over differing cultural values in the following manner:

Yes certainly, family conflict - the communication part or the traditional beliefs and traditional values collide with Western culture. It's always an issue. Older seniors, they have been here for a while, they always heard some stories so they know. They say, oh our grandchildren, we have to raise this way, we cannot spank them. Grandparents 
don't usually do that, it's the parents that intervene. They say oh my son works so hard, that's my in-laws, I can't say anything because this is Canada. So if they have been here for a long time, they know there's different value systems. But the [newcomer] older immigrant women, they complain a lot. They complain about their in-laws, their daughter in-law, they say oh my gosh I came to Canada and do this, this, this and they don't even show their respect. They probably show their respect in a different way, that's what I always tell them (Participant 1005).

Intergenerational family conflict can affect older adults' mental health, however this was not addressed in any of the interviews. Yet, the conflict is not necessarily just intergenerational but also between personal attitudes towards the Chinese and the Canadian health belief systems, which is explored in the next section.

\subsubsection{Different Health Beliefs}

The differences between Chinese health beliefs, along with the use of Traditional Chinese Medicine (TCM) and Western health beliefs were evident in the interviews. A brief description of TCM is that it is based on yin-yang natural forces that are opposite, yet dynamic and interdependent (Tang, Liu \& Ma, 2008). In TCM, yin refers to the organ itself, yang involves the function of the organ, while Qi (energy) and blood is circulated in the body (Tang, Liu \& Ma, 2008). Disease occurs if there is a disturbance to yin-yang, Qi or blood flow, or disharmony in the organs due to mood, lifestyle or climatic factors (hot/cold; Tang, Liu \& Ma, 2008). Treatment involves expelling or suppressing the cause and restoring balance (Tang, Liu \& Ma, 2008).

The Cantonese-speaking women participants preferred certain elements of TCM and 
retained Chinese health beliefs for maintaining their health. Both women did not like to take medications without knowing the side effects and implications on their body. Both women also believed in balanced, nutritional meals that kept the hot/cold balance (related to yin/yang). However, there was not a dichotomy between the Chinese and Western health beliefs. One doctor's touch, the entire body will be healed. Each time there was a sore throat, my mother would take me to see the Chinese herbalist/doctor and it would not be very expensive and like that, my throat would not be sore. [. . .] I bought some Chinese herbs for myself to boil soup/tonics for myself. In spring I take Chinese medicine for my osteoporosis. [. . . I believe in both medicines. It depends on what kind of illness. Both would be good. I like the Chinese herbalists' approach; they covered the entire body, not just an organ, very detailed and crystal clear (Participant 1002).

I believe in Chinese herbal medicine because they started from yin and yang. If I go back to China, I would bring back some Chinese herbal ingredients for soup... They are not for curing illnesses. Also some Chinese tea ... they are good for your yin \& yang in your body or sore throats. I believe Chinese medicine is very good. Western medicine is for fast cure but I don't like taking all the medications. Chinese medicine looks at the whole person and how to correct the imbalance. I also believe in Western medicine. The doctors are very knowledgeable in treating fevers or other disease. They don't correct yin and yang imbalance though. [. . . It depends on the type of illness. If serious illness, then Western medicine. I like that they have many methods like CT or MRI and the results can be found quickly. Chinese medicine doesn't have this, they rely on listening to your pulse. If it's a serious illness, I want Western medicine but if preventive care or 
illness prevention, then I would believe in Chinese medicine (Participant 1001).

The community worker participants reported similar health beliefs from their clients, who adopted a holistic approach to the body. Most clients used both Chinese and Western health approaches. One community worker reported that some of her clients do not believe in Western medicine (perhaps in relation to mental health) though.

They just trust traditional and don't believe Western. But our Chinese traditional [medicine], the effect is, you can't see it immediately. That's long term. We always say that it's strengthening your foundation. But for the medication, Western medication can have instant effect (Participant 1003).

She noted that clients might adopt a multidisciplinary approach for treatment in addition to medication, including exercise. Some might not adopt Western medical treatment, but instead use acupuncture or massages. This was another reason that some Chinese preferred a Chinese doctor due to their awareness of other Chinese methods of treatment. Take the example, ok when they have insomnia - a sleeping problem. If they go to a Chinese-speaking doctor, they will let them know about, other than the sleeping pills, they would also use some Chinese methods. For example, acupuncture and the massage and also maybe before going to sleep, they will put their feet in hot water. That's different, you know what I mean? But that's why if you are an English-speaking doctor, you don't understand why [people] distrust the pills, the sleeping pills. But if you come from the Chinese culture, the doctor can understand why the patient will do this way (Participant 1003).

The other community worker participant could not promote the Chinese approach 
because of her organization's mandate. She did acknowledge the differences in health approaches as reasons for intergenerational conflict.

They [The clients] are very emphasized on the holistic approach. They look at the body as yin and yang, that's the traditional. ... We talk about that too but we don't promote such things in our centre because we are Western medicine, but we won't criticize them either. So they practice tai chi, they practice all kinds of things, if they find it's relevant or meaningful to them then that's fine I guess. Yeah they talk to us about their herbal, the magic/functional food, talk about that. That's the reason for family conflict because of their beliefs with their children or adult children or in-laws, there's mixed families too right? [. . . They even have the cupping things. The cupping, they use on grandchildren for cupping but their adult children won't allow because it leaves marks, it's hard to explain in school. But they say it's useful. It is useful. They don't want to get questioned (Participant 1005).

The Cantonese-speaking women participants were a lot like other older Chinese adults that the community workers have spoken with. They adopted both Chinese and Western approaches to health. In the Discussion chapter this factor will be discussed, along with further analysis of the Canadian healthcare system. The numerous post-migration challenges from the participant interviews showed that these factors influenced physical and mental health for Cantonese-speaking women and the Chinese immigrant community.

\subsubsection{Systemic Barriers}

While there is some degree of agency in the post-migration challenges and a diversity of experiences, systemic barriers are social structures that cannot be avoided when interacting 
with the Canadian healthcare system. The systemic barriers identified within the interviews are: cultural barriers, healthcare services for Chinese, and government funding with participant recommendations for improvements.

\subsubsection{Cultural Barriers}

There are many differences between Chinese and Canadian cultures. These differences are especially noted in two subthemes of the participant interviews: cultural confusion and mental health.

\subsection{Cultural Confusion}

The Cantonese-speaking women participants did not talk about culture shock or differences in their habits, however the Chinese clients of the community worker participants noticed the cultural differences between their sending country and Canadian society. One community worker described it as culture shock for some of her clients.

But for the women, for the Cantonese community I mentioned that they have another, face a different type of issue. Even though the second generation, they came early, maybe they have come from maybe around 5 years old, they still face another culture shock. And sometimes people have different values in our Chinese traditional culture, maybe we need to have a different respect. But here when you are brought up here you will more emphasize on the individual for example (Participant 1003).

A community worker that works with both older non-Chinese adults and older Chinese adults noticed a big cultural difference surrounding the topic of wills and estates, which relates to another taboo subject for Chinese: death. Death is not discussed openly in Chinese culture, so no older Chinese adults attended a workshop about wills and estate planning even though 
some have lived in Canada for decades.

Yeah, I had a will and estate planning session. No Chinese coming. They don't want to face that. Maybe they think there's not much left, but for the older seniors they are supposed to know more. But still, that's something hard to face for them too (Participant 1005).

The diversity of countries that Chinese immigrants come from means that it is important to be mindful of their possible heterogeneity. Participant 1003 mentioned the differences between Hong Kong and Mainland China: two countries that had different political ideologies and therefore somewhat different upbringings for Chinese people. Other Chinese clients she has encountered were from Central America, since their families searched for a better life there and could speak Cantonese and English. However, their children may have identity confusion since they were born in Mexico, Cuba or Jamaica, are ethnically Chinese but now live in Canada. If their social identities cannot be negotiated in a satisfactory way, this can lead to losses in social support and other psychological distress (Heine, 2012). Culture and mental health was also a significant theme in the interviews, and this will be examined further in the next section.

\subsection{Mental Health}

The stigma surrounding mental health issues in Chinese culture is not a new discovery (Fang, 2010). The Chinese cultural norm of limited help-seeking behaviours from outside the family for personal problems is also not relatively new (Chen, Kazanjian \& Wong, 2009). As a result, mental health is a difficult subject to directly ask Chinese participants about. Cultural norms that are related to saving face dictate that one does not disclose any personal problems to strangers, which also means that seeking help outside of the family can be considered 
shameful to some (Kramer et al., 2002). Direct questions about mental health were not asked in our interviews. Instead, questions about stress, life satisfaction, or unexplained health problems were posed to the Cantonese-speaking participants. Mostly standard answers were given. Participant 1001 admitted to having sleep problems after immigration due to excessive thinking and worries before bedtime. She avoided taking an advanced level English class to prevent more anxiety and triggering higher blood pressure.

Participant 1002 was indirect about her mental health. She was anxious to meet for our interview and called several times before our meeting to ensure that we would not miss each other. In her responses, it seemed that she would be happy to get out of the house more. She had unexplained shoulder and knee pain, which could possibly be from stress or not enough physical activity. She talked about one racist incident, which might continue to affect her selfesteem. "I had some experience with people who looked down upon Asians. They swore at me. I heard that and I understand that" (Participant 1002). She included in an answer to one question about describing her health that she was not worried about dying or had any regrets when she died. Her response seemed out of place for such a general question and in breaking the Chinese taboo about death. Her response to the life satisfaction question was in a neutral tone, although her response was that she is satisfied with her life now. She did not elaborate further about that question and actually started to prepare to leave, although we were almost finished the interview. She was similar to many Chinese who cannot talk about personal problems with strangers, but the social context clues were there. At least two major factors that affected her mental health were likely that she recently separated from her husband of over 40 years and was still adjusting to living in Canadian society as a new immigrant. 
Participant 1002 is someone who could use counseling or mental health support in Western psychology terms, but as both community workers stated, using words such as counseling or mental health around the Chinese community will not attract clients. Instead, modifications to psychological terms need to be made for Chinese clients to use services surrounding mental health. Participant 1003 organized workshops for the community but chose the title, "relief from anxiety" for talking about anxiety disorders. She used different strategies for people to be aware of their mental health issues, and subjects that can relate to everyone such as talking about mood.

I mentioned before [about] the managing emotions, we also adopt the CBT [cognitive behavioural therapy] approach. We will talk about emotion ABCs. But we will not say to the clients, to our participants, oh now we adopt CBT, we will just talk about it. We work with the community, we use layman [words], we seldom use the psychological, the Greek psychology. For them, it's meaningless, they just want to know how to treat themselves (Participant 1003).

The lady was grieving that time, you know she needs counseling but you cannot say it's counseling. Just say, we will have some people help you, you can talk to her, she might help you to find something. Yeah, so you really cannot use such words like counseling (Participant 1005).

Other issues surrounding mental health were discussed with community workers who could speak more openly about the subject compared to the Cantonese-speaking participants. One community worker acknowledged the limited help-seeking behaviours among Chinese. "We always say that, we will try to solve the issue or problem by ourselves instead of going to 
the community to seek help because they always have a Chinese belief from the older generation, the teaching" (Participant 1003).

The inability for Chinese to express mental health issues openly means that a more socially acceptable manner is to display physical symptoms. One community worker gave an example of one of her clients.

He said when he came here he's family reunion [status], the children brought him here but he has nothing to do, he doesn't speak English, he doesn't understand so he cannot go out. ... He said he was so sick, physically sick not mentally sick, [but] it was depression, depressed. But he thinks he's physically, something's wrong physically. So he goes to see the family doctor and after a 3 month period, he found a family doctor and goes to see him every week. ... So he went to the doctor all the time. The doctor told him not to come in to see him (Participant 1005).

It was her older Chinese adults group, her "social medicine" that stopped him from trying to see the doctor every week and lifted his depression. Yet the doctor did not know about the patient's social context to understand that it was a mental health issue, not a physical one. Doctors need to be more aware of psychological issues that can present themselves physically in all patients, but especially with Chinese patients.

While the cultural barrier surrounding mental health exists in Chinese culture, the community worker participants aim to help the Chinese community to solve their mental health issues. Participant 1005 facilitates an older Chinese adults' group that allows them to discuss health topics and provide social support to solve their issues. Participant 1003 organizes mental health workshops with a variety of titles that addresses mental health issues in an indirect way. 
She found that most of her clients prefer to solve health issues or concerns themselves instead of asking their children to help. She has also participated on a Toronto radio program on AM1430 with TCM practitioners and a Chinese medical school student to discuss with some patients about their use of TCM to treat their depression. Her organization also runs a family support group for those with family members with mental health issues and advice for them. She found that often, family members are unwilling to violate the family relationship to commit a family member to get help, even if they hurt themselves or others.

Consequently, community workers have an important role in bridging the Chinese community and health services. The community workers did have encouraging experiences to demonstrate that perhaps over time, some Chinese are willing to approach or overcome this cultural barrier. Participant 1003 has a waiting list for her workshops every year, which shows that there is interest in learning more about mental health.

Our [Cantonese] culture is quite significantly affected by the Hong Kong culture. In Hong Kong right now the people, they're more willing to disclose emotional issues. . . A lot of the people are willing to step out to the community to participate. I think it's so encouraging to the workers when we see there's significant changes in the past ten years that people are more willing to talk about this topic. [. . .] I think that's a long term battle. It's not just one time thing that suddenly they will change because I think our culture and the mass media influence, it's difficult to change the concept about themselves (Participant 1003).

Both community worker participants also mentioned other activities that their organizations coordinate for their clients: arts and crafts, lion dance, community gardening, 
Qigong (Chinese exercise), cultural events (i.e., Chinese New Year), and community walks.

These activities help support mental health for Chinese clients through methods of social support, engaging clients in activities that they might enjoy, and for them to live independently. For those that require more assistance after workshops or group activities, clients are referred to an intake worker or social worker to provide personalized assistance.

There is more work to be done in bringing mental health awareness to the Chinese community. Yet not all areas of Toronto or all Chinese may be able to access these services. The next section will examine the availability of health services to Chinese in Toronto.

\subsubsection{Health Services for Chinese}

The interviews with community workers covered what health programs and services are currently available specifically for the Chinese population. Participant 1005 's organization integrates their health programs with neighbourhood community development. There are less concentrated programs for the Chinese population, however her work covers a variety of Chinese groups. Her previous outreach work at another organization was not just for Chinese, but she tried to bring more health awareness to the Chinese community. She would hold workshops or go to the media to talk about health issues and health risks for Chinese immigrants.

Participant 1003 focuses on prevention and promotion of mental health among the Chinese community. Her organization tries to bridge gaps between mainstream mental health organizations and Asian communities. "I just got the community requests that they want to register for a course, because not so many organizations that will organize these mental health workshops to the clients or to the general public" (Participant 1003). These workshops help 
bring more awareness so her clients can think about whether "they maybe have some of the mental health issues and then they will seek help in advance. That's our purpose, earlier identification and early treatment as possible" (Participant 1003).

More solutions for families with a member requiring mental health support are needed though. The Ontario Mental Health Act (1990) allows physicians, police officers, and judges to commission an involuntary admission for a mental health assessment. For community workers like Participant 1003, they can advise the family member to go to the family doctor to complete a form, or to call to get the form and force the client to go to a hospital to seek help for treatment. Yet as mentioned in the Mental Health subsection, many family members do not want to violate this relationship.

It's difficult because in Canada, they have some policy to guide us. We can't force people, if they are unwilling to seek help, then it's difficult to do outreach. That's why most of the time there are family members to seek help, they suspect that their family member with mental health concerns (Participant 1003).

The waiting lists for her workshops and the numerous partnerships with other organizations could mean that there is an unmet need for culturally competent mental health services or workshops. "I always am invited by different organizations to provide community workshops. For example, CareFirst and another organization, wellness centres. We have a good partnership, relationship with other community organizations including social organizations and churches and other religion organizations" (Participant 1003). The community worker participants also gave limited responses about other organizations in Toronto that perform similar work. 
The geographic location of the organizations will also play a role in accessibility for clients that often favour services in close proximity. So while Participant 1003 and 1005 provide needed mental health and physical health services respectively for their service location, do other Chinese also need these services but are unable to access them? It is difficult to provide culturally-specific physical health or mental health services independently in a multicultural city like Toronto, so how can more organizations or service providers become culturally competent? An increase in culturally competent physical health or mental health services would depend on funding, which will be addressed in the next section.

\subsubsection{Participant Recommendations and Government Funding}

The issue of government funding depends on the level of government and the organization or services that are under that government's jurisdiction. There were a number of instances in the interviews when the participants raised the theme of additional government funding or improvements. To start with, LINC English classes could use more funding, which is funded by the federal government. Participant 1001 remembered when there was funding available for their LINC English classes to visit other parts of the city to help learn more about Canada and Canadians. She wished that more funding was available so that they could know more about Toronto and Canada through their LINC English classes. Participant 1002 thought that the teaching in LINC English classes could be improved. She heard that there are some people who take the classes for a long time without improvement in their English.

LINC English classes also do not teach basic medical terms that might be helpful to put new immigrants at ease with interacting with the Canadian healthcare system. Instead, Participant 1005 had one session to teach older Chinese adults about words that they might 
come across in the healthcare system so that they know for themselves whether it was right or that their issues were addressed. Perhaps this would be a useful class for all new immigrants to have so that they are equipped with essential knowledge for accessing Canadian healthcare.

The provincial government is responsible for funding healthcare in each province. The participants mentioned a few areas of healthcare that could use extra funding. Participant 1001 would like to have test results for medical tests that are required for older adults to be given to the patients for free. Her thoughts were that this would allow patients to track their own health and would save the government money since this could prevent certain illnesses. She also thought that the government could be looking more closely at preventative medicine.

Therefore, I suggested the "Preventive Medical Care" for the government. There was a saying: "Prevention is better than cure". It would save a lot of money so I don't need to see the doctor as often. There would be no surgery needed and [they] can offer a nutrition class (Participant 1001).

Both Cantonese-speaking women would also like Chinese herbalists or TCM doctors to be covered, however there would need to be lobbying efforts for governments to accept TCM and acupuncturists in provincial medical plans. British Columbia is the only province to allow acupuncture treatments to be covered for premium assistance recipients since 2008 (British Columbia Ministry of Health, 2008). Ontario officially required all acupuncture practitioners to be registered in April 2013, while they regulated TCM practitioners since 2006 (Ontario Ministry of Health, 2013).

One community worker wished that she could have another caseworker to effectively manage the issues her older adults' group discusses. "The issues we've identified in the group, I 
don't have much time to follow up. So I feel sad about that. . . I I would love to have another person to help me. I'm the only person here working on this" (Participant 1005). The lack of personnel also meant that potential solutions could not be implemented to tackle issues like older adults' social isolation in the winter.

One way we could do is friendly visiting programming, but it's hard to do that. I don't have the manpower for that. Or a peer support system. ... Some of the seniors' language issues, that's still there. That hinders the whole process (Participant 1005). As for mental health services, the community worker thought that partnerships would improve accessibility for Chinese clients and provide improved services for them.

For me, I would have a partnership with different social organizations. We would be active to involve the community to let them have some kind of opportunity to access the services. Right now, you can see that they have different organizations to still provide mental health issues or another [for] physical health, then there's one of different entry points, they can still seek help (Participant 1003).

Both Cantonese-speaking women also noted the long wait times for doctors and felt that this should be improved. Wait times are a major issue in Canadian healthcare, however practical solutions are yet to be found (Canadian Health Coalition, 2015a).

The systemic barriers covered a variety of themes that could influence access to healthcare services that the Cantonese-speaking older immigrant women could not control. Community workers also added evidence to themes that they experienced or that were mentioned by their Chinese clientele. Intersections of systemic barriers, post-migration challenges and social categories are discussed in the next chapter. 


\section{Discussion}

From an intersectional framework, the interactions between themes should be examined for their affect on health, along with the social and historical context. Four major intersections are discussed: family issues with other post-migration challenges, Chinese culture and health beliefs with Canadian culture and health beliefs, immigration experiences with social categories, and government funding for the healthcare system with culture. Limitations and future directions of this research study are also discussed in this chapter.

\subsection{Intersecting Family Issues with other Post-migration Challenges}

One major subtheme that intersected with other subthemes was about family issues. Family can be a major reason that older Chinese people immigrate to Canada (Preston, Kobayashi \& Siemiatycki, 2006). There are expectations that older Chinese adults will help with family duties such as caring for grandchildren, and other family business, household or care work as a result of being sponsored for immigration (Lam, 1994). However, parents of adult children may not live with them to avoid conflict over family roles (Kramer et al., 2002).

In the case of Participant 1002, immigration partially led to the separation of spouses. There is concern for the health of family class immigrants because under the family reunification policy, sponsors are financially responsible for their relative for 10 years (or 20 years for 2014 applicants; CIC, 2014), thus family class immigrants are not eligible for publicly funded programs such as hospitalization and home care (Chard, Badets \& Howatson, 2000; Simmons, 1990). Therefore, socioeconomic status is another intersecting subtheme with family issues. Although the Cantonese-speaking women in this study did not explicitly say that finances affected their access to healthcare, they were concerned about certain costs 
surrounding their health. Another study also found that Chinese immigrant women who were dependent on their children financially would determine their utilization of the healthcare system from this situation (Wang, 1997).

Family issues also intersect with learning a new language because if there is a family member available to translate during medical appointments, then the need for older Chinese immigrant adults to learn a new language could be mitigated. Translation services through family members did not occur for the Cantonese-speaking women, but the community workers mentioned that this occurs in some families. There is also work to be done with creating trust with older adults and interpreters, whether it is a family member or a health services provider. Participant 1005 revealed that older Chinese immigrant adults that did not speak English felt fear or distrust in those situations. "It's uncertainty too that makes them tense. Language of course, you don't have skill, you don't know then you certainly feel unsafe" (Participant 1005). She tried to lessen their fear and distrust through a session about common English medical terms, however it is unknown if there are many others that provide this information to older Chinese immigrant adults. In another study, the Chinese immigrant women felt demoralized and embarrassed over family dependence for translation services (Wang, 1997). The dependence on family members can also leave older Chinese immigrant adults to be socially isolated from their peers or Canadian society. Their strong words to Participant 1005 describing their situation as an "overseas prison" should not be taken lightly. As such, social isolation for older adults also intersects with family issues.

From the intersecting subthemes mentioned above, the importance of family well-being to support older Chinese immigrant adults' integration has been neglected in research so far. 
The power of the sponsor over the parents or grandparents is a reversal of Chinese cultural norms based on the respect of elders and filial piety, a Confucian moral tradition that adult children take good care of their aged parents (Wang, 1998). Older Chinese immigrant adults are dependent on their adult children for their social integration and economic security (CAC, 2008). Yet based on the evidence from other sections in this paper regarding cultural norms, older Chinese immigrant adults are unlikely to disclose even more serious family issues like elder abuse or intimate partner violence. Community workers already raised the issue of intergenerational conflict within families, which could be more widespread than reported due to cultural norms that prevent disclosure.

The combination of the stresses of family integration, immigration policies that require 10-20 years of sponsorship, and other policies that do not recognize older adult immigrants' contributions could lead families to take out their frustration on their older adult family member. Older adult immigrants who are sponsored by family are in vulnerable situations they don't want to break the family apart when conflict or abuse occurs, they don't qualify for social assistance, and they face integration issues with Canadian society. The families have limited solutions outside of the constraints of Canadian immigration policy. Perhaps this requires recognition on the part of Canadian and ethnic communities about this gap in the immigration system to provide more support or services for older adult immigrants and to advocate for policy changes. 


\subsection{Intersecting Chinese Culture and Health Beliefs with Canadian Culture and}

\section{Health Beliefs}

Intersectionality is especially relevant to capture the diversity of the human experience for those who do not fit neatly into one homogeneous cultural group. Third culture kids (a child born in a third country whose parents are from two different cultures; Tokuhama-Espinosa, 2003), immigrants adapting to a new country, or children of immigrants are faced with examining multiple cultural values and identities as part of acculturation (Heine, 2012). Perhaps depending on the context, elements of more than one culture are adopted as a form of blending (a mix of two cultures; Heine, 2012), code-switching (contextual public presentation of the self; Anderson, 1998) or frame-switching (psychological switching between cultural selves; Heine, 2012).

The two main cultures in this paper are Canadian and Chinese. One major difference concerns health beliefs, another concerns mental health, while the other major difference is about cultural values. First I will address health beliefs. Some may expect that Chinese immigrants should just adopt the Western medical approach upon immigration. However that view is ignorant of the history of Chinese medicine that dates back at least two thousand years (National Center for Complementary and Integrative Health, 2013). There are great efforts underway to produce more evidence-based research about the effectiveness of Chinese medicine (Yeung, 2006). In China, TCM and Western medicine are integrated and there are studies that may eventually lead to a combination of the two systems (Tang, Liu \& Ma, 2008). Perhaps part of the attraction to TCM is that it uses a natural and holistic approach in responding to disease treatment and it does care about a person's well-being (Yeung, 2006). 
The Western medical model that involves pills, doctors that may not fully investigate a medical problem, and waiting until symptoms develop does not sit well with those who experienced TCM, such as the Cantonese-speaking women in this study. While the women do not choose one approach over another, the Western medical model does not always allow for other health beliefs to be considered (Fadiman, 1997). Therefore, TCM should be considered with Western medicine as more studies show increasing use among all Canadians of complementary and alternative medicines (Quan et al., 2008).

Due to the holistic nature of TCM, psychology and mental health remains a foreign concept for many Chinese immigrants. The area of psychology requires further evidence that Euro-American based psychological terms apply to other populations in the world (Henrich, Heine \& Norenzayan, 2010; Marsella \& Pedersen, 2004). Consequently, the approach that was adopted by the community workers in this research study that adapted Western mental health terms to be approachable for Chinese immigrants needs to be integrated into the Canadian mental health practice. These adaptations may prove to be useful for other ethnic groups as well. In addition, cultural competence surrounding the usefulness of asking about a person's social context should be considered, given the evidence in the context surrounding Participant 1002's mental health. Other approaches that are mindful about limited help-seeking behaviours or limited discussion of personal problems are also needed for Chinese immigrant clients.

A number of differing cultural values between Chinese immigrants and Canadians were evident in this paper. It cannot be expected that Chinese immigrants will give up on all of their cultural values upon arrival in Canada. Some adapt to their situation in Canada by relieving their children of the filial piety expectation (Lam, 1994). Some try to save face through avoiding 
conflicts with their family members, such as the participants of this research study. Other Chinese immigrants avoid topics like death even though they have lived in Canada for decades, which Participant 1005 experienced at a wills and estates session. The cultural values need to be kept in mind when providing or adapting community or health services to Chinese clients. It may also be useful for community workers like Participant 1003 and Participant 1005 to develop or become part of a network of Chinese service providers to share information about client patterns or develop initiatives.

\subsection{Intersecting Immigration Experiences with Social Categories}

This section aims to examine intersecting social categories of gender, ethnicity, and age for Cantonese-speaking older immigrant women. The Cantonese-speaking women did not explicitly mention gender issues that they faced after immigration to Canada. In fact, Participant 1001's work and English levels in comparison to her husband's situation differs from the usual account of immigrant men that work and have better English levels. Community workers noted that their clientele consisted mainly of Chinese women participating in their sessions or activities, however both were encouraging Chinese men to become more involved.

The Cantonese-speaking women participants noted circumstances surrounding their own age in the interviews. Participant 1001 thought that it was generous of the government to provide language classes to older adult immigrants. Participant 1002 wanted to volunteer or work but found ageism instead.

When they have seen me in motion personally doing the manual labour for an aging woman, they asked me not to do them. They think that I am too old for manual labour. [. . .] When I faced the interviewer, his comment was "Why are you not retired?" I was 
so discouraged by the prejudice towards aging older adults (Participant 1002).

The community worker that works regularly with older adult groups highlighted that older Chinese women are very active. "Chinese women are very active, they will do all kinds of things, they do the dancing group, they're singing, the folk dance, then summertime they try to do gardening" (Participant 1005). Therefore, the ageism towards older Chinese women is unwarranted since they prefer to be active.

Participant 1001 did not mention any acts of discrimination towards her because of her ethnicity. Participant 1002 noted experiencing discrimination because of prejudice towards Asian people. The community workers also did not hear about experiences of discrimination towards their clients. Yet Participant 1003 stated that systemic barriers exist for those who cannot speak the official languages in Canada for accessing healthcare. These systemic barriers also exist within the Canadian immigration system, which intersects with the social categories of participants in this research study. The systemic barriers are invisible until we examine the social and historical context of immigration in Canada.

The social context of gender is relevant for many Chinese immigrant women. Many studies have explored the systemic structure of patriarchy or gender inequalities that oppresses Chinese immigrant women (Fong, 1999; Ho, 2006; Man, 1997; Man, 2004; Poy, 2013; Preston \& Man, 1999). While gender was not a central issue in this research study, it is noted that other research exists in which Chinese women felt the double burden of being racialized as an ethnic minority and of being a woman in Canada (CCNC, 1992; Poy, 2013). Issues surrounding gender will be further explored in the next section.

Race continues to exist as a sociological term that incorrectly describes physical 
attributes of ethnicity. Racism influenced the Canadian immigration system until the 1960s when the points system was introduced (Dua, 2000). The view of Chinese people in the $19^{\text {th }}$ century was based on a European hierarchy of race that justified viewing others as inferior (Pieterse, 2002). Canadian nation-building favoured Anglo-Saxon immigration and social organization, not the increase of racialized immigrants until after World War II (Dua, 2000).

The notion that racialized women would disrupt British nation-building through the creation of communities resulted in the exclusion of Chinese women until 1950 (Dua, 2000; Poy, 2013). Although federal policies aimed to promote equality in employment for visible minorities and women, systemic discrimination continued for the more educated wave of Chinese women from Hong Kong (Poy, 2013; Public Service Alliance of Canada, 2013). AntiChinese sentiments existed in Toronto and Vancouver throughout the late 1980s and early 1990s from those that resented the success and power of non-European immigrants and cultural communities (Poy, 2013). Foreign property owners, many of whom are Chinese, remain an issue in Vancouver and Toronto due to the high costs of renting or buying property in the cities (CBC News, 2015). As a result, some Chinese women that migrate to Canada may not be aware of their social location in Canadian society in which they are racialized and Chinese.

Ageism derives from ageist attitudes, which are thought to be composed of feelings due to a person's age, stereotypes about what someone is like because the person is of a certain age, and differential treatment due to their older age (Kite \& Wagner, 2004). There remains a gap in health knowledge due to the limited studies on older persons, including international studies that do not gather statistics on people over the age of 50 (Canadian Women's Health Network, 2012). A Canadian medical student also lamented about the amount of ageism 
embedded into the structure of their curriculum and training (Stall, 2012). It is not a surprise then that health studies on older women are limited, and even more so for older immigrant women. Older immigrant women may also be described as having a "triple jeopardy": age, gender, and ethnicity (Chundamala, Matsuo \& Peng, 2006). Meanwhile, more attention should be paid to older immigrant women since they are more vulnerable and dependent than nonimmigrants when adjusting to a new environment (Chundamala, Matsuo \& Peng, 2006; Mehr, 2013). It is especially important for older immigrant women since the social context can affect a person's psychological adjustment to their new country (Chen, 2010; Lou \& Beaujot, 2005; Tang, Oatley \& Toner, 2007).

Racism, patriarchy, and ageism are systems of oppression that can negatively impact older Chinese immigrant women in Canada. Although these systems may not apply to all older Chinese immigrant women, the fact that this is the case for some Chinese and other immigrant women requires that more recognition of a triple burden is needed. As a result, a multi-faceted approach to eliminating these systemic barriers is needed, especially as the number of older immigrant adults grows in major cities across Canada due to an aging population.

\subsection{Intersecting Government Funding for the Healthcare System with Culture}

The Canadian healthcare system was designed for all residents to have access to prepaid, medically necessary hospital and physician services (Health Canada, 2010). The federal agency, Health Canada has a mandate to implement the Canada Health Act (1985), which is the federal law that sets the criteria and conditions for provincially insured health services and extended health services to receive federal cash contributions. The organization of healthcare 
delivery services is based on the ideology of self-care (Anderson, Blue \& Lau, 1991; Health Canada, 2002).

Self-care is linked to other Western ideologies: individualism, neoliberalism and capitalism. The neoliberal ideology is based on the notion that each human being should be free to pursue happiness without government interference and be personally responsible for their welfare without government aid (Finn, 2007). Among government policies, neoliberalism places an emphasis on individualism and market-led economic and social restructuring (Whiteside, 2009). Individualism places the responsibility upon oneself, and not embedded in other social structures. Capitalism thrives from individual actions for the pursuit of profit (Marx \& McLennan, 2000).

Neoliberal policies have become problematic for public healthcare (medicare) in Canada. The door has being left open for the erosion of socialized medicine due to the federal and provincial governments' preference to privatize elements of healthcare (Whiteside, 2009). The federal government has continuously decreased healthcare funding while healthcare costs increased since 1977, including the latest cut of $\$ 36$ billion over the next 10 years beginning in 2017 (Canadian Health Coalition, 2015b; Whiteside, 2009). The provinces turned to publicprivate partnerships and the privatization of health support services in attempts to fix the funding shortfall, which commodified the future development of healthcare (Whiteside, 2009). Yet the healthcare system's quality becomes undermined when profitability is more important than providing necessary services and places the onus on individuals.

The expectation of self-care or individual responsibility for healthcare will not help immigrant women if resources to enable them to do so are not in place (Anderson, Blue \& Lau, 
1991). For example in this research study, Participant 1001 would like to track her own health but currently medical test results are not automatically provided to a patient. There are also fewer resources available for Chinese women who may require translators, social workers, or respite services in a city like Edmonton (Stewart et al., 2006). The Canadian healthcare system also marginalizes older adult immigrants who do not conform to what is provided by the Western health model. There are no provisions to provide non-Western food to patients in hospitals, or for nurses to speak to patients in their language (Leung \& McDonald, 2001). Some progressive elements are adopting the cultural competence approach in which healthcare professionals acknowledge and respect cultures and cultural practices of their clients, and develop awareness of their own cultural values and beliefs that shape interactions with their clients (Canadian Medical Protective Association, 2014; Fadiman, 1997; Gustafson, 2008; Leininger, 1996). However this approach has not been adopted as part of national health policy, so there are varied practices across Canada, with only Alberta and Nova Scotia creating guides available regarding cultural competence for all medical service professionals (Alberta Health Services, 2009; Nova Scotia Department of Health, 2005). The inability of the neoliberal state to fund linguistically and culturally sensitive services places the onus on family members or community organizations to provide these services (Brotman, 2003; Stewart et al., 2006). Language as a barrier to health services is also a form of discrimination, however it can easily be seen as an individual rather than a systemic problem (Brotman, 2003). In fact, the invisibility of institutional racism surrounding the language barrier in health services does not make the issue easily addressed (Brotman, 2003). Nevertheless, more progressive health policies will not likely be implemented if provincial health systems are constantly battling for funds from the federal 
and provincial governments.

The Canadian medical system tends to have a patriarchal approach. The hierarchy in the medical system is related to political power since the time of inception of male professional associations of doctors that influenced decision-makers (Valiani, 2011). The current biomedical model for doctors is based on treatments, diagnoses, and seeing body parts as separate, as opposed to an approach taught to nurses, which involves caring for the whole person (Valiani, 2011). In another study, some Chinese immigrant women described this hierarchy in the Canadian healthcare system as "a doctor is an empire" (Wang, 1997). For this study, how is it that despite having Cantonese-speaking doctors, some of the Cantonese-speaking women's medical issues remained untreated? It is unknown if gender was an issue, but it is noted that both women in this study had male Chinese doctors that refused to investigate their medical issues further. A preference for a more holistic approach to medical treatment due to increases in immigrant populations in Canada may not support the continued Western biomedical model. Evidence towards differences in Canadian immigrant health compared to the Canadian-born population requires different strategies (Hyman, 2007; Lai, 2004; Lou \& Beaujot, 2005; OxmanMartinez et al., 2005) that may include alternative treatments (Quan et al., 2008).

There is a gap in national health policy discussions regarding concerns specific to immigrant populations (Asanin \& Wilson, 2008). The most recent national health commissions, the Commission on the Future of Healthcare in Canada (Romanow, 2002) and the Standing Senate Committee on Social Affairs, Science and Technology Study on the State of the Healthcare System in Canada (Kirby \& LeBreton, 2002), did not give adequate consideration to the health needs of immigrant populations in the concerns or recommendations from the 
discussions (Asanin \& Wilson, 2008). It was argued that current immigrant health practices and policies were found in the Immigration and Refugee Protection Act (2001) rather than in national health legislation (Gushulak \& Williams, 2004). As such, the Canadian healthcare system needs to address the needs of a growing immigrant population and ensure access is available to all.

\subsection{Limitations and Future Research}

This research study has a few limitations. First, the experiences with healthcare services of the Cantonese-speaking women are contextual to Toronto, which has a large Cantonesespeaking Chinese population. Cantonese-speaking women in other Canadian cities with lower proportions of Cantonese-speaking people may have a different healthcare experience. Second, it is important to keep in mind that the progressive nature of intersectionality means that currently there are limited studies to compare methodology with, and that the focus on heterogeneity may make it difficult to unify efforts to address inequalities (Hankivsky et al., 2010). Third, since few community workers specifically work with older Cantonese-speaking immigrant women then this group's specific issues are hard to pinpoint. However, there is evidence of their issues from this study. Fourth, due to limited space I cannot include other topics in this MRP that were discussed in the interviews that deserve to be publicized (i.e., positive post-migration changes, differences between the Chinese and Canadian healthcare systems, current experiences of Mandarin-speaking young mothers). Fifth, due to a limited research period then the number of Cantonese-speaking women was fewer than anticipated. More women could provide other areas of difference that were not identified in this study. Future directions for this study could include increasing efforts to build partnerships 
with community organizations to benefit the Chinese or local community. A community-based approach could be used to explore different needs of Chinese immigrant women in different areas of Toronto or across Canada. The study could be expanded to include Cantonese-speaking health professionals and their experiences with their Chinese clientele. Also, other studies were successful with random telephone surveys with Chinese households, which may be another recruitment technique to be used.

\section{Conclusion}

The richness of qualitative research is evident in the interviews of this research study. There is a lot to be learned from a research study involving non-English-speaking participants from the translations involved to the practical limitations regarding a university telephone system to the descriptions of implicit cultural terms, I learned a lot through the whole process. Through this research study I gained cultural knowledge that enriches my own cultural identity. I hope that this research will also help improve the experiences of older Chinese immigrants.

The perceptions of health for these Cantonese-speaking women were centered around a holistic approach to health and echoed some of the beliefs of Traditional Chinese Medicine. Their health experiences varied even though they often encountered Cantonese-speaking health professionals. Language did not prevent them from accessing healthcare services, but did cause them anxiety about receiving proper medical attention. Other post-migration challenges and systemic barriers contributed to the health experiences of these Cantonesespeaking women, supplemented by the observations of the community workers.

This research study was important in its efforts to expand research knowledge about the health experiences of those who cannot fluently speak an official language in Canada. This 
study also highlights the voices of older racialized women and their experiences with the healthcare system. Their perceptions of health and their social context are important to consider for those who work in the health services sector. The intersectional approach tackled the intersections in social categories, post-migration challenges, and the numerous structural barriers on all sides of the health system.

Such variances in health experiences point to the notion that all of the social determinants of health should be considered. Cultural competence among health professionals should be a minimum standard to account for the numerous factors that can affect health. Moreover, it should be advocated that the Canadian healthcare system should be adequately funded and measures should be taken to include immigrant health issues in national health policies. Otherwise, immigrant voices will once again be marginalized and left out of dominant discourse. 


\section{References}

Alberta Health Services. (2009). Enhancing Cultural Competency - A Resource Kit for Health Care Professionals. Retrieved on August 25, 2015 from:

https://fcrc.albertahealthservices.ca/pdfs/Enhancing_Cultural_Competency_Resource_Kit .pdf

Anderson, E. (1998). The social ecology of youth violence. Crime and Justice, 65-104.

Anderson, J. M., Blue, C., \& Lau, A. (1991). Women's perspectives on chronic illness: Ethnicity, ideology and restructuring of life. Social Science \& Medicine, 33(2), 101-113.

Asanin, J. \& Wilson, K. (2008). "I spent nine years looking for a doctor": Exploring access to health care among immigrants in Mississauga, Ontario, Canada. Social Science \& Medicine [H.W. Wilson - SSA], 66(6), 1271.

Atlantic Centre of Excellence for Women's Health. (1998). Women's Perceptions of the determinants of Health and Well-Being. Voices Project. Retrieved April 16, 2015 from: http://www.dal.ca/diff/Atlantic-Centre-of-Excellence-for-Womens-Health/projects-andpublications/aboriginal-black-and-immigrant-women/voices-research-project.html

Borrell, C., Muntaner, C., Benach, J., \& Artazcoz, L. (2004). Social class and self-reported health status among men and women: what is the role of work organisation, household material standards and household labour? Social science \& medicine, 58(10), 1869-1887.

British Columbia Ministry of Health. (2008). Acupuncture added as supplementary MSP benefit. Retrieved on August 25, 2015 from: http://www2.news.gov.bc.ca/news_releases_20052009/2008HEALTH0031-000429.htm

Brotman, S. (2003). The limits of multiculturalism in elder care services. Journal of Aging Studies, 17(2), 209-229.

Calnan, M. (1986). Maintaining health and preventing illness: a comparison of the perceptions of women from different social classes. Health Promotion International, 1(2), 167-177.

Canada Health Act, RSC 1985, c. C-6 (1985).

Canadian Health Coalition. (2015a). Wait Times. Retrieved on August 25, 2015 from: http://healthcoalition.ca/main/issues/wait-times/

Canadian Health Coalition. (2015b). What is the Health Accord? Retrieved on August 25, 2015 from: http://healthcoalition.ca/what-is-the-health-accord/ 
Canadian Protective Medical Association. (2014). When culture and medicine intersect.

Retrieved on August 25, 2015 from: http://www.cmpa-acpm.ca/-/when-medicine-andculture-intersect

Canadian Women's Health Network. (2012). Aging, Women and Health. Retrieved on August 25, 2015 from: http://www.cwhn.ca/en/node/42957

Caulford, P. \& D'Andrade, J. (2012). Health care for Canada's medically uninsured immigrants and refugees: Whose problem is it? Canadian Family Physician, 58(7), 725-727.

CBC News. (2015). Foreign buyers driving luxury real estate sales, Re/Max says. Retrieved on Sept 1, 2015 from: http://www.cbc.ca/news/business/luxury-real-estate-foreign-buyers1.3211587

Chard J., Badets J. \& Howatson L. (2000). Immigrant women. In: M. Almey, S. Besserer, J. Chard, C. Lindsay, J. Normand, V. Pottie Bunge, H. Tait \& N. Zukewich (Eds.) Women in Canada 2000: A Gender-based Statistical Report, pp. 189-217. Statistics Canada No. 89-503-XPE. Statistics Canada, Ottawa.

Chen, A.W. (2010). Immigrant access to mental health services: Conceptual and research issues. Canadian Issues, 51.

Chen, A. W., Kazanjian, A., \& Wong, H. (2009). Why do Chinese Canadians not consult mental health services: health status, language or culture?. Transcultural Psychiatry, 46(4), 623641.

Chinese Advisory Council of United Way of Peel Region. (2008). The Needs and Challenges of the Chinese Community in Peel Region. Retrieved on March 30, 2015 from: http://www.unitedwaypeel.org/pics/reports/chinese_community_report.pdf

Chinese Canadian National Council. (1992). Jin guo: Voices of Chinese Canadian women. Toronto: Women's Press.

Chundamala, J., Matsuo, T., \& Peng, I. (2006). Older immigrant women's health: From the triple jeopardy perspective to cultural competency. Older immigrant women's health literature review. Health Status and Health Needs of Older Immigrant Women: Individual, Community, and Societal and Policy Links project.

Citizenship and Immigration Canada. (2014). Guide 5772 - Application to Sponsor Parents and Grandparents. Retrieved November 16, 2014 from: http://www.cic.gc.ca/english/information/applications/guides/5772ETOC.asp 
City of Toronto. (2015). Diversity - Toronto Facts. Retrieved on August 26, 2015 from: http://www1.toronto.ca/wps/portal/contentonly?vgnextoid=dbe867b42d853410VgnVC M10000071d60f89RCRD\&vgnextchannel=57a12cc817453410VgnVCM10000071d60f89RC $\mathrm{RD}$

Collins, E. \& Guruge, S. (2008). Theoretical Perspectives and Conceptual Frameworks. Working With Immigrant Women: Issues \& Strategies for Mental Health Professionals. In Guruge, S. \& Collins, E. (Eds). Ontario: Centre for Addiction \& Mental Health

Crenshaw, K.W. (1989). Demarginalizing the Intersection of Race and Sex: A Black Feminist Critique of Antidiscrimination Doctrine, Feminist Theory and Antiracist Politics. University of Chicago Legal Forum, 1989, 138-67.

Crenshaw, K. W. (1991). Mapping the Margins: Intersectionality, Identity Politics, and Violence against Women of Color. Stanford Law Review, 43(6), 1241-99.

Creswell, J. W. (2007). Qualitative inquiry \& research design: Choosing among five approaches. Thousand Oaks: Sage Publications.

Das Gupta, T. (2000). Families of Native Peoples, Immigrants and People of Colour. In Barbara Crow and Lise Gotell (Eds.), Open Boundaries: A Canadian Women's Studies Reader (pp. 215-230). Prentice Hall Canada.

Dlamini, N., Anucha, U., \& Wolfe, B. (2012). Negotiated positions: Immigrant Women's views and experiences of employment in Canada. Affilia, 27(4), 420-434. doi:10.1177/0886109912464479

Dua, E. (2000). “The Hindu Women's Question": Canadian Nation Building and the Social Construction of Gender for South Asian-Canadian Women (pp. 55-72) in Agnes Calliste and George J. Sefa Dei (Eds.) Anti-Racist Feminism: Critical Race and Gender Studies. Halifax: Fernwood.

Fadiman, A. (1997). The spirit catches you and you fall down: A Hmong child, her American doctors, and the collision of two cultures. New York: Farrar, Straus, and Giroux.

Fang, L. (2010). Mental health service utilization by Chinese immigrants: barriers and opportunities. Canadian Issues, 51.

Finn, E. (2007). The Right Is Wrong and the Left Is Right: Cutting Through the Neoliberal Bafflegab. Canadian Centre for Policy Alternatives.

Fong, J. (1999). Where do they belong? The fate of Chinese immigrant women. Canadian Woman Studies, 19(3), 64. 
Fowler, N. (1998). Providing primary health care to immigrants and refugees: The North Hamilton experience. CMAJ : Canadian Medical Association Journal = Journal De I'Association Medicale Canadienne, 159(4), 388-391.

Gee, E.M., Kobayashi, K.M., Prus, S.G. (2004). Examining the healthy immigrant effect in mid- to later life: Findings from the Canadian Community Health Survey. Canadian Journal on Aging, 23 (Suppl. 1), pp. S61-S69.

Guruge, S., Berman, R., Tyyska, V., Murphy Killbride, K., Woungang, I., Edwards, S., \& Clune, L. (2009). Implications of English proficiency on immigrant women's access to \& utilization of health services. Retrieved on January 31, 2015 from: https://tspace.library.utoronto.ca/bitstream/1807/17685/1/guruge_berman_etal.pdf

Gushulak, B. D., \& Williams, L. S. (2004). National immigration health policy: Existing policy, changing needs, and future directions. Canadian Journal of Public Health / Revue Canadienne De Sante'e Publique, 95(3), 127-129.

Gustafson, D. (2008). Are Sensitivity and Tolerance Enough? Comparing Two Theoretical Approaches to Caring for Newcomer Women with Mental Health Problems. Working With Immigrant Women: Issues \& Strategies for Mental Health Professionals. In Guruge, S. \& Collins, E. (Eds). Ontario: Centre for Addiction \& Mental Health

Hankivsky, O. (2014). Intersectionality 101. The Institute for Intersectionality Research \& Policy, SFU. : Burnaby, British Columbia, Canada.

Hankivsky, O., Reid, C., Cormier, R., Varcoe, C., Clark, N., Benoit, C., \& Brotman, S. (2010). Exploring the promises of intersectionality for advancing women's health research. International Journal for Equity in Health, 9(1), 5-5. doi:10.1186/1475-9276-9-5

Health Canada. (2002). Supporting Self-care: A Shared Initiative 1999-2002. Retrieved on August 25, 2015 from: http://www.hc-sc.gc.ca/hcs-sss/pubs/hhrhs/2002-selfautocollabor/index-eng.php

Health Canada. (2010). Canada's Health Care System (Medicare). Retrieved on August 25, 2015 from: http://www.hc-sc.gc.ca/hcs-sss/medi-assur/index-eng.php

Heine, S. J. (2012). Cultural psychology. New York: W.W. Norton.

Henrich, J., Heine, S. J., \& Norenzayan, A. (2010). Most people are not WEIRD. Nature, 466(7302), 29-29.

Ho, C. (2006). Migration as Feminization? Chinese Women's Experiences of Work and Family in Australia, Journal of Ethnic and Migration Studies, 32:3, 497-514. 
Hunting, G. (2014). Intersectionality-informed qualitative research: A premier. Institute for Intersectional Research and Policy, SFU: Burnaby, British Columbia, Canada.

Hyman, I. (2007). Immigration and health: reviewing evidence of the healthy immigrant effect in Canada. Joint Centre of Excellence for Research on Immigration and Settlement.

Hyman, I. (2009). Racism as a determinant of immigrant health. Ottawa: Strategic Initiatives and Innovations Directorate of the Public Health Agency of Canada.

Immigration and Refugee Protection Act, SC 2001 (2001).

Kim, I., Carrasco, C., Muntaner, C., McKenzie, K., \& Noh, S. (2013). Ethnicity and postmigration health trajectory in new immigrants to Canada. American Journal of Public Health, 103(4), e96.

Kirby M, \& LeBreton M. (2002). The health of Canadians. The federal role. Recommendations for reform. The Standing Senate Committee on Social Affairs, Science and Technology: Ottawa.

Kite, M.E. \& Wagner, L. S. (2004). In T.D. Nelson (Ed.)., Ageism: Stereotyping and prejudice against older persons. Boston: MIT Press.

Kramer, E. J., Kwong, K., Lee, E., \& Chung, H. (2002). Cultural factors influencing the mental health of Asian Americans. Western Journal of Medicine, 176(4), 227-231.

Kushniryk, A., Titus-Roberts, J., \& Wertz, E. (2014). Immigration as a Catalyst for Increased Health Awareness: Immigrant Women Define Health and Health Decision Making. Journal of Immigrant and Refugee Studies, 12, 3, 172-190.

Kwok, S., Mann, L., Wong, K., \& Blum, I. (2009). Dietary habits and health beliefs of Chinese Canadians. Canadian Journal of Dietetic Practice and Research, 70(2), 73-80.

Lai, D. W. (2004). Health status of older Chinese in Canada: Findings from the SF-36 health survey. Canadian Journal of Public Health/Revue Canadienne de Sante'e Publique, 193197.

Lai, D. W., \& Chau, S. B. (2007). Predictors of health service barriers for older Chinese immigrants in Canada. Health \& social work, 32(1), 57-65.

Lam, L. (1994). Self-assessment of health status of aged Chinese-Canadians. Journal of Asian and African studies, 29(1-2), 77-90.

Leininger, M. (1996). Culture care theory, research, and practice. Nursing Science Quarterly, 9(2), 71-78. doi:10.1177/089431849600900208 
Leung, H. H., \& McDonald, L. (2001). Chinese immigrant women who care for aging parents, Toronto Chapter. Chinese in Pacific Rim Countries: Social support and integration. Hong Kong: Hong Kong University Press, 1-16.

Li, K. M. (2009). Transnationalism, Citizenship and Sense of Belonging among Elderly Hong Kong Immigrants in Canada. (Master's thesis, Queen's University).

Liang, W., Yuan, E., Mandelblatt, J. S., \& Pasick, R. J. (2004). How do older Chinese women view health and cancer screening? Results from focus groups and implications for interventions. Ethnicity \& health, 9(3), 283-304.

Lou, Y. \& Beaujot, R. (2005). What Happens to the 'Healthy Immigrant Effect': The Mental Health of Immigrants to Canada. PSC Discussion Papers Series: 19(15).

Lu, C., Sylvestre, J., Melnychuk, N., \& Li, J. (2008). East meets West: Chinese-Canadians' perspectives on health and fitness. Canadian Journal of Public Health = Revue Canadienne De Santé Publique, 99, 1.)

Man, G. (1997). Women's work is never done: Social organization of work and the experience of women in middle-class Hong Kong Chinese immigrant families in Canada. Centre for Excellence for Research on Immigration and Settlement \& American Sociological Association: Toronto, ON.

Man, G. (2004). Gender, work and migration: Deskilling Chinese immigrant women in Canada. Women's Studies International Forum, 27(2), 135-148.

Marsella, A. J., \& Pedersen, P. (2004). Internationalizing the counseling psychology curriculum: Toward new values, competencies, and directions. Counselling Psychology Quarterly, 17(4), 413-423.

Marx, K., \& McLellan, D. (2000). Karl Marx: Selected writings. Oxford: Oxford University Press.

McMaster Research Centre for the Promotion of Women's Health. (1999). Final Report. Retrieved October 31, 2014 from: http://www.mcmaster.ca/mrcpowh/final.htm

Meadows, L. M., Thurston, W. E., \& Melton, C. (2001). Immigrant women's health. Social science \& medicine, 52(9), 1451-1458.

Mehr, F. S. (2013). Addressing Factors Related to Depression \& Mental Health in Elderly Chinese Immigrant Women in Ontario. (Doctoral dissertation, University of Ottawa). 
Milan, A. \& Vezina, M. (2010). Senior Women. Statistics Canada. Retrieved on August 26, 2015 from:

http://www.statcan.gc.ca/pub/89-503-x/2010001/article/11441-eng.htm\#a4

Morgan, S., Hanley, G., Cunningham, C., \& Quan, H. (2011). Ethnic differences in the use of prescription drugs: a cross-sectional analysis of linked survey and administrative data. Open Medicine, 5(2), e87.

Morrow, M., Varcoe, C., \& Hankivsky, O. (2007). Women's health in Canada: Critical perspectives on theory and policy. Toronto [Ont.: University of Toronto Press.

National Centre for Complementary and Integrative Health (2013). Traditional Chinese medicine: An introduction. Retrieved on August 25, 2015 from: http://nccih.nih.gov/health/whatiscam/chinesemed.htm

Newbold, B. K. (2005). Self-rated health within the Canadian immigrant population: Risk and the healthy immigrant effect. Social Science and Medicine, 60 (6), pp. 1359-1370.

Neuman, W.L. (2006). Social Research Methods: Qualitative and Quantitative approaches. (6th ed.). Boston: Allyn \& Bacon.

Ng, R. (1988). The politics of community services: Immigrant women, class and state. Toronto: Garamond.

Nova Scotia Department of Health (2005). A Cultural Competence Guide for Primary Health Care Professionals in Nova Scotia. Primary Health Care Section. Retrieved on August 25, 2015 from:

http://www.healthteamnovascotia.ca/cultural_competence/Cultural_Competence_guide _for_Primary_Health_Care_Professionals.pdf

Ontario Mental Health Act (1990). R.S.O. 1990, c. M.7

Ontario Ministry of Health (2013). Strengthening Safe, Regulated Traditional Chinese Medicine. Retrieved on August 25, 2015 from: http://news.ontario.ca/mohltc/en/2013/3/strengthening-safe-regulated-traditionalchinese-medicine.html

Oxman-Martinez et al., J., Hanley, J., Lach, L., Khanlou, N., Weerasinghe, S., \& Agnew, V. (2005). Intersection of Canadian policy parameters affecting women with precarious immigration status: A baseline for understanding barriers to health. Journal of Immigrant Health, 7(4), 247-258. doi:10.1007/s10903-005-5122-2

Pieterse, J. (2002). Europe and its Others. In D. Goldberg \& J. Solomos (Eds). A Companion to Racial and Ethnic Studies. Oxford: Blackwell Publishing Inc. 
Poy, V. (2013). Passage to promise land: Voices of Chinese immigrant women to Canada. Montréal: McGill-Queen's University Press.

Preston, V., Kim, A., Hudyma, S., Mandell, N., Luxton, M., \& Hemphill, J. (2013). Gender, race, and immigration: Aging and economic security in Canada. Canadian Review of Social Policy, 90.

Preston, V., Kobayashi, A., \& Siemiatycki, M. (2006). Transnational urbanism: Toronto at a crossroads. In Vic Satzewich and Lloyd Wong (Eds.). Transnational Identities and Practices in Canada (pp. 91-110). Vancouver: UBC Press.

Preston, V. \& Man, G. (1999). Employment experiences of Chinese immigrant women: An exploration of diversity. Canadian Woman Studies, 19(3), 115.

Public Health Agency of Canada. (2011). What Determines Health? Retrieved December 9, 2014 from: http://www.phac-aspc.gc.ca/ph-sp/determinants/index-eng.php

Public Service Alliance of Canada. (2013). A Brief History of Employment Equity in Canada. Retrieved April 6, 2015 from: http://psacunion.ca/brief-history-employment-equitycanada

Quan, H., Lai, D., Johnson, D., Verhoef, M., \& Musto, R. (2008). Complementary and alternative medicine use among Chinese and white Canadians. Canadian Family Physician, 54(11), 1563-1569.

Raphael, D. (2009). Social determinants of health: Canadian perspectives. Toronto: Canadian Scholars' Press.

Romanow, R. J. (2002). Building on values: The future of health care in Canada. Commission on the Future of Health Care in Canada: Saskatoon, Sask.

Saechao, F., Sharrock, S., Reicherter, D., Livingston, J. D., Aylward, A., Whisnant, J., ... \& Kohli, S. (2012). Stressors and barriers to using mental health services among diverse groups of first-generation immigrants to the United States. Community mental health journal, 48(1), 98-106.

Sanmartin, C., \& Ross, N. (2006). Experiencing difficulties accessing first-contact health services in Canada: Canadians without regular doctors and recent immigrants have difficulties accessing first-contact healthcare services. Reports of difficulties in accessing care vary by age, sex and region. Healthcare Policy = Politiques De Santé, 1(2), 103-119.

Satzewich, V. N., \& Liodakis, N. (2010). 'Race' \& ethnicity in Canada: A critical introduction. Don Mills, Ont: OUP Canada. 
Simmons A. (1990) 'New wave' immigrants: origins and characteristics. In: S. Halli, F. Trovato \& L. Drieger (Eds) Ethnic Demography: Canadian Immigrant, Racial and Cultural Variations, pp. 141-159. Carleton University Press, Ottawa.

Stall, N. (2012). Time to end ageism in medical education. CMAJ : Canadian Medical Association Journal = Journal De l'Association Medicale Canadienne, 184(6), 728-728.

doi:10.1503/cmaj.112179

Statistics Canada (2006). Ethnic origins, 2006 counts, for census metropolitan areas and census agglomerations - 20\% sample data. Retrieved on August 26, 2015 from:

http://www12.statcan.ca/census-recensement/2006/dp-pd/hlt/97-

562/pages/page.cfm Lang $=E \&$ Geo $=C M A \&$ Code $=535 \&$ Data $=$ Count $\&$ Table $=2 \&$ StartRec $=1 \&$ Sort=3\&Display=All\&CSDFilter $=5000$

Statistics Canada. (2007). Profile of ethnic communities in Canada. Retrieved on August 26, 2015 from:

http://www.statcan.gc.ca/pub/89-621-x/89-621-x2006001-eng.htm

Stewart, M. J., Neufeld, A., Harrison, M. J., Spitzer, D., Hughes, K., \& Makwarimba, E. (2006). Immigrant women family caregivers in Canada: Implications for policies and programmes in health and social sectors. Health \& Social Care in the Community, 14(4), 329-340. doi:10.1111/j.1365-2524.2006.00627.x

Tang, J. L., Liu, B. Y., \& Ma, K. W. (2008). Traditional Chinese medicine. Lancet, 372, 9654, 193840.

Tang, T. N., Oatley, K., \& Toner, B. B. (2007). Impact of life events and difficulties on the mental health of Chinese immigrant women. Journal of Immigrant and Minority Health, 9(4), 281290.

Taylor-Powell, E., \& Renner, M. (2003). Analyzing qualitative data. University of Wisconsin Extension. Retrieved on August 13, 2015 from: http://learningstore.uwex.edu/pdf/g365812.pdf

Teelucksingh, C. \& Galabuzi, G. (2007). Working Precariously: The Impact of Race and Immigration Status on Employment Opportunities and Outcomes in Canada. In T. Das Gupta, C.E. James, R.C.A. Maaka, G.E. Galabuzi, \& C. Anderson (Eds.), Race and Racialization: Essential Readings. Toronto: Canadian Scholars' Press Inc, 202-208.

Todd, L., \& Hoffman-Goetz, L. (2011). Predicting health literacy among English-as-a-secondlanguage older Chinese immigrant women to Canada: Comprehension of colon cancer prevention information. Journal of Cancer Education, 26(2), 326-332. 
Tokuhama-Espinosa, T. (2003). The multilingual mind: issues discussed by, for, and about people living with many languages. Greenwood Publishing Group.

UN General Assembly, Universal Declaration of Human Rights, 10 December 1948, 217 A (III). Retrieved November 8, 2014 from: http://www.un.org/en/documents/udhr/

Valiani, S. (2011). Rethinking Unequal Exchange: the global integration of nursing labour markets. University of Toronto Press.

Vissandjée, B., Weinfeld, M., Dupéré, S., \& Abdool, S. (2001). Sex, gender, ethnicity, and access to health care services: Research and policy challenges for immigrant women in Canada. Journal of International Migration and Integration/Revue de l'integration et de la migration internationale, 2(1), 55-75.

Wan, F.L.M. (2004). Language, social networks, and parenting in the lived experiences of five working-class Chinese immigrant women in Toronto: An ethnographic study. (Doctoral dissertation, OISE, University of Toronto).

Wang, J. (1998). The Confucian Filial Obligation and Care for Aged Parents. World Congress of Philosophy Papers. Retrieved on August 25, 2015 from: https://www.bu.edu/wcp/Papers/Comp/CompWang.htm

Wang, L., \& Hu, W. (2013). Immigrant health, place effect and regional disparities in Canada. Social Science \& Medicine, 98, 8-17.

Wang, S. (1997). The experiences of Chinese immigrant women with the health care delivery system in Canada. (Master's thesis, Dalhousie University).

Wang, S., \& Lo, L. (2005). Chinese Immigrants in Canada: Their Changing Composition and Economic Performance. International Migration, 43(3), 35-71.

Whiteside, H. (2009). Canada's Health Care" Crisis": Accumulation by Dispossession and the Neoliberal Fix. Studies in political economy, 84.

Wong, Y. L. R., \& Tsang, A. (2004). When Asian immigrant women speak: From mental health to strategies of being. American Journal of Orthopsychiatry, 74(4), 456-466.

Wood, J., \& Newbold, K. B. (2012). Provider perspectives on barriers and strategies for achieving culturally sensitive mental health services for immigrants: A Hamilton, Ontario case study. Journal of International Migration and Integration, 13(3), 383-397.

Yeung, H. W. (2006). Chinese Medicine: a peer-reviewed open access journal for evidence-led Chinese medicine. Chinese Medicine, 1(1). Retrieved on August 25, 2015 from: http://www.cmjournal.org/content/1/1/1 